\title{
Multiple drivers and extreme events collapse social- ecological systems sooner
}

\author{
Simon Willcock ( $\nabla$ simon.willcock@rothamsted.ac.uk) \\ Rothamsted Research https://orcid.org/0000-0001-9534-9114

\section{Gregory Cooper} \\ University of Sheffield \\ John Addy \\ Rothamsted Research \\ John Dearing \\ University of Southampton
}

\section{Article}

Keywords: climate change, modelling, regime shift, resilience, stress, tipping point

Posted Date: December 14th, 2021

DOI: https://doi.org/10.21203/rs.3.rs-1158662/v1

License: (c) (1) This work is licensed under a Creative Commons Attribution 4.0 International License. Read Full License 
1 Title: Multiple drivers and extreme events collapse social-ecological systems sooner

2 Authors: Simon Willcock ${ }^{\mathrm{a}, \mathrm{b} * \S}$, Gregory S. Cooper ${ }^{\mathrm{c}, \mathrm{d} \S}$, John Addy and John A. Dearing ${ }^{\mathrm{e}}$.

3

4

5

6 Institutions:
a) Rothamsted
Research,
Harpenden,
Hertfordshire,
AL5 2JQ,
UK. simon.willcock@rothamsted.ac.uk; john.addy@rothamsted.ac.uk

b) School of Natural Sciences, Bangor University, Bangor, Gwynedd, LL57 2DG, UK. s.willcock@bangor.ac.uk

c) Department of Geography, University of Sheffield, Sheffield, S10 2TN, UK. g.s.cooper@sheffield.ac.uk

d) Institute for Sustainable Food, University of Sheffield, Sheffield, S10 2TN, UK.

e) Geography and Environmental Science, University of Southampton, Southampton, SO17 1BJ, UK. j.dearing@soton.ac.uk

* Corresponding author

$\S$ Joint $1^{\text {st }}$ authors.

\section{Abstract}

The world's ecosystems are undergoing unprecedented changes due to the impact of climate change and local human activities. A major concern is the possibility of tipping points where ecosystems and landscapes change abruptly to undesirable states. We consider what happens to the timing of tipping points when current stresses strengthen whilst systems experience additional stresses and/or extreme events. We run experiments on four mathematical models that simulate tipping points in lake water quality, the Easter Island community, the Chilika lagoon fishery, and forest dieback. We show that the strongest impacts occur under increasing levels of primary stress, but additional and more extreme stresses in all four models bring the tipping points significantly closer to today. Translating the results to the real world underlines the need for humanity to reduce damaging disturbances and global warming, and to be vigilant for signs that natural systems are degrading more rapidly than previously thought.

Key words: climate change, modelling, regime shift, resilience, stress, tipping point.

\section{Introduction}

For many observers, UK Chief Scientist's John Beddington's argument that the world faced a 'Perfect Storm' of global events by $2030^{1}$ has now become a prescient warning. Recent mention of 'ghastly futures' ${ }^{2}$, 'widespread ecosystem collapse' ${ }^{3}$, and 'domino effects on sustainability goals' ${ }^{4}$ tap into a growing scientific consensus that the Earth is rapidly destabilising through connected tipping points 
(critical thresholds where the system changes abruptly ${ }^{5}$ ). Kareiva and Carranza ${ }^{6}$ even speculate on 'end-of-world' scenarios involving transgressing planetary boundaries (climate, freshwater and ocean acidification), accelerating reinforcing (i.e. positive) feedback mechanisms and multiplicative stresses. However, these views are based more on recent observations, narratives and simple indices of environmental degradation than any deeper systems-based analysis or modelling 7,8 . Here, we explore how the growing stress from human activities, global warming and more interactions between systems could cause the world's social-ecological systems to collapse sooner than anticipated.

The recent history of attempts to anticipate rapid changes in the Earth system shows two main perspectives. The first uses a top-down tipping point framework and argues that different regional 'global climate' elements may change rapidly as global mean temperatures increase and thresholds are crossed ${ }^{9}$. IPCC AR6 ${ }^{10}$ describes 15 tipping points, including the Greenland Ice Sheet (GIS), Atlantic Meridional Ocean Circulation (AMOC), Tropical and Boreal forests. In each case, the likelihood of tipping by 2100 is highly uncertain with low probability, with the exception of the Amazon tropical forest where there is only low confidence that the system will not tip during the 21st century. The second takes a more bottom-up approach arguing that human transformation and fragmentation of the Earth surface, caused by global warming but also through land use activities, are causing many localised tipping points to be crossed ${ }^{11,12}$. As local thresholds are crossed, abrupt changes are seen in diverse environments (e.g. terrestrial biodiversity, fish yields, ocean oxic zones, lake water quality, water supplies $)^{13}$ with threats to the future social-ecological sustainability and resilience of Earth's sub-systems ${ }^{14}$. Some approaches cut across both these top-down and bottom-up perspectives, notably the idea of planetary boundaries with safe and dangerous spaces ${ }^{15}$, and the focus on extreme events of various kinds, like hurricanes, wildfires, drought, flooding and epidemics ${ }^{16,17}$.

These two approaches are linked in several studies through the risk posed by tipping elements influencing each other across space and time, causing abrupt system changes to accelerate. Wunderling et $a .^{18}$ used expert opinion ${ }^{9,19}$ to suggest that more interactions between tipping points tend to destabilise the network. They argue that strengthening interactions between five of the main tipping elements (i.e., GIS, West Antarctic Ice Sheet, AMOC, El Niño-Southern Oscillation and Amazon forest) effectively push the critical threshold temperatures to lower warming levels, thus reducing the overall stability of the climate system. A similar finding also arises from Klose et al.'s conceptual model of coupled Earth subsystems which shows tipping in one system triggering tipping in a coupled system at a point lower than the intrinsic tipping point of the affected sub-system ${ }^{20}$. They also note that, in addition to direct coupling, indirect 'diffusive' interactions (such as rising atmospheric $\mathrm{CO}_{2}$ ) could become the coupling mechanism that leads to a change in the threshold value of a slowly changing 
driver ${ }^{20}$. Taking a network approach, Krönke et al. found that systems with large average clustering coefficients and spatially structured networks (e.g. the Amazon forest) are more vulnerable to tipping cascades than more disordered network topologies ${ }^{21}$. Such arguments were used to explain Cooper et al.'s finding from both real-world regime shifts and mathematical models that large complex systems collapse disproportionately faster ${ }^{22}$.

An empirical database of 30 observed and modelled regime shifts allowed Rocha et al. ${ }^{23}$ to describe networks of drivers, responses and feedbacks. They identified shared drivers, one-way and two-way domino cascades and two-way cascades (cf. ${ }^{20}$ ) where there are hidden feedbacks. Forty five percent of the tipping points showed evidence for structural interdependence meaning that the abrupt change observed in one system will trigger a shift in another system. Shared drivers are most common across similar land uses ${ }^{23}$. Potential domino effects were only found in time, not space, and related to tipping points in systems with slow temporal dynamics, such as monsoon weakening, thermohaline collapse and GIS collapse ${ }^{23}$. Lade et al. ${ }^{24}$ extend the interrogation of existing datasets to produce a dynamic assessment of linkages. They reviewed previously studied interactions to identify a dense network of interactions between the planetary boundaries and used control theory to produce a linear equilibrium model to assess feedbacks. Only 6 out of 35 interactions identified include balancing (i.e., negative) feedbacks ${ }^{24}$. Thus, the majority of the resulting cascade feedback mechanisms are reinforcing and predominantly amplify human impacts on the Earth system, thereby shrinking the 'safe operating space' for future impacts.

The above studies describe Earth tipping points and their potential to interact but also show that we lack a clear generalisation about which combinations of trends, feedbacks and multiple stresses are likely to produce the deadliest impacts, nor an understanding about plausible rates and timescales ${ }^{25}$. One issue is that the network studies have employed techniques where connections are mainly described by their presence/absence, strength or probability of causal links, and with assumed linear relationships to the impacted system, rather than capturing the outcomes from a natural, emergent process. Also, modelling of tipping points within critical transition frameworks has tended to focus on bifurcations caused by slow, single drivers changing environmental conditions, such as a

100 shift from clear to turbid lake water, brought about by higher levels of dissolved phosphorus ${ }^{26}$. 101 However, Ashwin et al's $\mathrm{s}^{27}$ mathematical tripartite classification of critical transitions includes, in 102 addition to slow driver bifurcations, rate-induced (fast/cumulative driver) and noise-induced (extreme 103 event) tipping points. Despite calls for more experimental evidence of climate variability and extremes 
104 on ecosystems ${ }^{28,29}$, we are unaware of published modelling studies that simulate the interaction of 105 fast drivers, multiple drivers and system noise on the timing of tipping points in real world systems.

107 The evidence for increasing rates of change in key drivers at the global scale is strong. Despite decreases in global birth rates and increases in renewable energy generation, the general trends of population, greenhouse gas concentrations and economic drivers, such as gross domestic product, is upwards 8,30 , often with acceleration through the 20th century. Similar non-stationary trends for ecosystem degradation ${ }^{31}$ imply that unstable sub-systems are common. Furthermore, there is strong

112 evidence globally for the increased frequency and magnitude of heatwaves and heavy precipitation

113 events $^{10}$. Examples include the sequence of European summer droughts since $2015^{32}$, and fire-

114 promoting phases of the tropical Pacific and Indian ocean variability ${ }^{33}$. It also seems certain that the

115 number of extreme events that cause fatalities or normalised financial costs above a range of

116 threshold values has increased since $1980^{8}$. Human influence has also likely increased globally the

117 frequency of concurrent heatwaves and droughts, already implicated in reduced crop yields ${ }^{34}$ and

118 regional fires and flooding ${ }^{10}$. Overall, global warming even at $1.5^{\circ} \mathrm{C}$ will increase the frequency of 119 unprecedented extreme events, raise the probability of compound events (e.g. ${ }^{35}$ ), make multiple 120 system failures more likely ${ }^{36}$, and make rarer events more common ${ }^{10}$.

122 Thought experiments informed by these observations suggest that stronger interactions between 123 systems may be expected to increase the numbers of drivers of any one system, change driver 124 behaviour and generate more system noise. For example, for any particular element (e.g. the Amazon 125 forest) it is possible to envisage a time sequence that starts with one main driver (e.g. deforestation), 126 then multiple drivers (e.g. deforestation plus global warming), more noise through extreme events 127 (e.g. more droughts and wildfires), with additional feedback mechanisms that enhance the drivers 128 (e.g. diminished internal water cycle and more severe drought). A vicious circle therefore emerges 129 with drivers generating noisier systems as climate variability and the incidence of extreme events 130 increases. The circle becomes faster as reinforcing feedbacks accelerate connections or human 131 activities increase stress levels. Thus, we predict that any increase in the number of drivers and/or the 132 strength or frequency of extreme events (i.e. noise) will bring forward the collapse of systems already 133 under pressure from slow and fast/cumulative drivers, but particularly so for fast-onset systems ${ }^{37}$.

135 Ideally, further insight about the likelihood of such tipping cascades could come from Earth system 136 models. Unfortunately, the current generation lack detailed vegetation dynamics ${ }^{38}$ which means that 137 key terrestrial feedbacks (e.g. C sinks/sources across all biomes ${ }^{39-41}$ ) are simplified or ignored. Thus, it 138 seems unlikely that large-scale Earth system models adequately simulate emergent outcomes from 
multiple drivers and connectivity ${ }^{25}$. As an alternative we turn attention to systems models that can be externally manipulated to simulate internal emergent tipping dynamics at local and regional scales as if they were impacted through stronger connections to other systems. The ability of system dynamics models (SDMs) to capture feedback-loops, delays and interactions between social and ecological components ${ }^{42,43}$ has motivated their use in various recent studies of social-ecological sustainability and resilience $22,44-46$. Therefore, guided by Ashwin et al.'s ${ }^{27}$ typology of tipping points, we aim to generalise the dynamics of increasing the numbers of drivers, their rates and variability (as proxies for stronger interactions between systems and noise) on the speed at which tipping points are reached in four model social-ecological SDMs (Figure 1): Chilika fishery ${ }^{22,44}$, Lake phosphorus ${ }^{47,48}$, 148 Easter Island ${ }^{49}$, and a modified version of The Hadley Centre Dynamic Global Vegetation Model (TRIFFID) of forest dieback ${ }^{37,50}$.

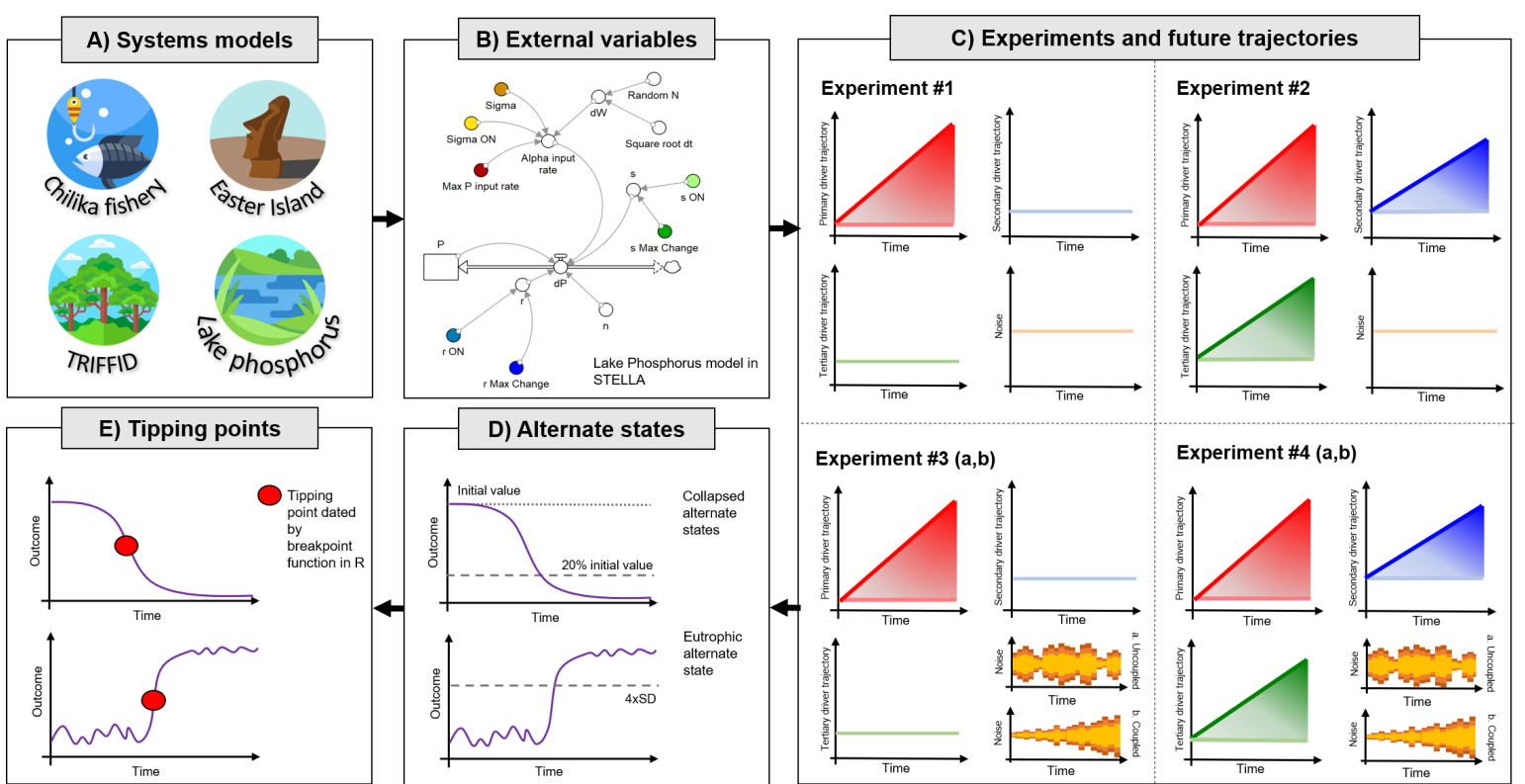

Figure 1: Schematic overview of the framework developed to explore the influence of slow driver trajectories and/or noise on the timing of tipping points: $(A)$ the four systems models simulated in this study (Methods Section 1); (B) illustration of a system dynamics model (Lake Phosphorus model) with its external slow and noisy drivers depicted in colour (Methods Section 2); (C) depiction of the four experiment types (Methods Sections 2.1-2.3), ranging from changes in the primary baseline driver only (Experiment \#1) to changes in all drivers simultaneously (Experiment \#2): darker colours schematically represent steeper trajectories and/or higher noise levels; (D) the two linear techniques used to check whether outcomes shift into an alternate state (Methods Section 3.1) - top is applied to Lake Chilika, Easter Island and TRIFFID, bottom is applied to Lake Phosphorus; (E) depiction of the timeseries tipping point date (Methods Section 3.1). Icons in (A) are sourced from www.flaticon.com

\section{Results}

164 As described in the Methods, the four models each have a primary (baseline) slow driver (Figure 1: 165 black points), where linear changes in their trajectories over time can initiate tipping point dynamics 
166 in their respective outcome variable (Chilika: fish population; Easter Island: human population; Lake 167 phosphorus: lake phosphorus concentration; TRIFFID: tree coverage). As expected, when the strength 168 of the primary slow driver in each model is increased, the modelled systems collapse sooner (as 169 defined by a statistical breakpoint in their temporal trends; see Methods Section 3; Figure 1). We show 170 that in three of the models (Easter Island, TRIFFID and Lake Phosphorus), changes in primary driver 171 strengths have comparatively larger reductions in the absolute time before the tipping point is 172 reached at low driver levels (i.e., when the primary driver is relatively weak), when compared to the 173 same change at higher values of the primary driver, although the percentage value by which the 174 tipping point is brought forward is relatively consistent (Figure 2). In other words, the absolute 175 advance in the tipping point may be reduced as driver strength increases, but the percentage shift in 176 the time point is likely similar. For example, increasing the normalised baseline driver strength from 1770.3 to 0.5 decreases the median time until system collapse by 3 years (9.4\%), 341 years (28.9\%), 92 178 years (38.7\%) and 245 unitless timesteps (29.0\%), for Chilika, Easter Island, TRIFFID, and Lake 179 Phosphorus respectively (Figure 2). In turn, increasing the normalised driver strength from 0.5 to 0.7 180 decreases the median time until system collapse by 4 years (13.8\%), 175 years (20.9\%), 40 years 181 (27.4\%), and 166 unitless timesteps (27.6\%) across the four models respectively. 


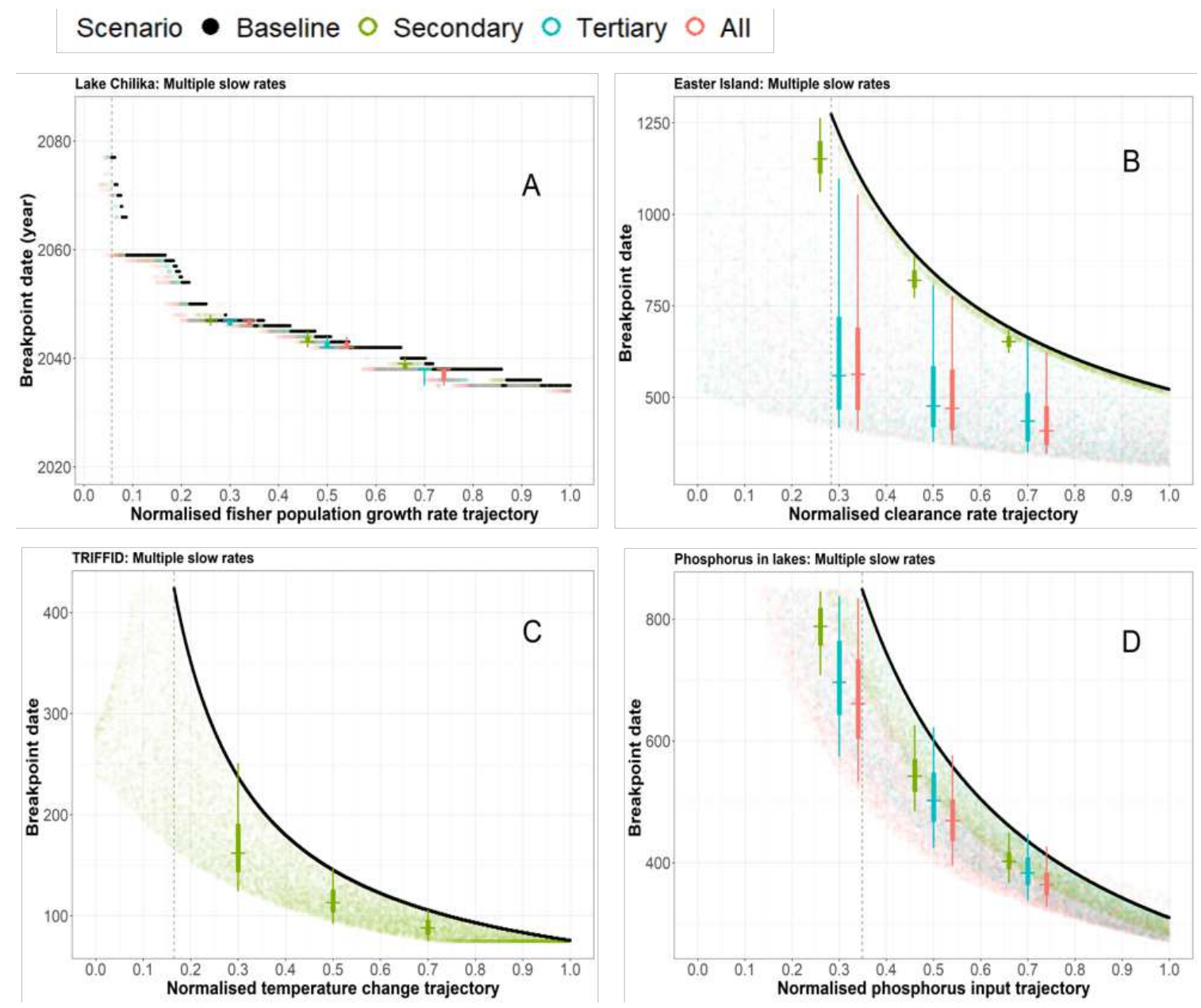

Figure 2 - The relationship between the breakpoint date and the primary (baseline) slow driver (normalised between $\mathbf{0}$ and $\mathbf{1}$ ) for the individual (black) and multiple (coloured) drivers. For each of the scenarios (i.e. driver combinations), the boxplots depict the $2.5 \%, 25 \%, 50 \%, 75 \%$ and 97.5\% breakpoint date percentiles, in each of the following ranges along the x-axis: $0.25-0.35$, 0.45-0.55, 0.65-0.75. Subplots: (A) Chilika model, primary slow driver: fisher population growth, secondary driver: climate change, tertiary driver: fish price; (B) Easter Island model, primary slow driver = tree clearance, secondary driver: agricultural carrying capacity, tertiary driver: tree mortality; (C) TRIFFID model, primary slow driver: temperature change, secondary driver: disturbance rate; (D) Lake Phosphorus model, primary slow driver: phosphorus external input, secondary driver: phosphorus recycling rate, tertiary driver: phosphorus sedimentation rate. The dashed vertical lines denote the minimum primary driver strength associated with a breakpoint.

Increasing the strength of multiple (i.e., secondary and tertiary) drivers further reduces the breakpoint date (Figure 2: coloured points). As with a single driver, this effect is more noticeable on unit time at low driver levels, but the percentage effect is relatively consistent. For example, at a normalised driver strength of 0.3 , the Easter Island model shows that the addition of two extra drivers brings the median tipping point forward from timestep 1179 to timestep 563 (reduction: 616 years [52.2\%]), but the same extra drivers added to the main driver at 0.5 normalised levels only advances the date of collapse from timestep 838 to timestep 470 (reduction: 368 years [43.9\%]). These results are consistent with the TRIFFID and Lake Phosphorus models (TRIFFID: 76 years [31.9\%] and 18 years [17.0\%] reduction 
191 for one additional driver; Lake Phosphorus: 187 timesteps [22.0\%] and 225 timesteps [16.5\%] 192 reduction for two additional drivers, for 0.3 and 0.7 normalised primary slow driver levels respectively;

193 Figure 2). By contrast, the addition of two extra drivers only brings forward the median tipping points 194 in the Chilika model by 0 years [0\%] and 2 years [8\%], for 0.3 and 0.7 normalised primary slow driver 195 levels respectively - perhaps reflecting the dominance of the primary driver (i.e., the growth of the 196 fisher population) on fishery dynamics. Variation around these median responses (Figure 2: boxplots) 197 is determined by the relative strength of the additional drivers, with the addition of a weak driver 198 bringing forward the start of system collapse substantially less than the addition of a strong secondary 199 driver (Figure S1). In addition to earlier tipping point dates, extra drivers can also cause the system to collapse at levels where it would be resilient to the primary slow driver in isolation. For example, across the 1000 timesteps of the Lake Phosphorus model, the system is stable at normalised baseline driver rates up to 0.348 (i.e. lake phosphorus concentration does not go through a breakpoint; Figure 2D). However, the addition of a single secondary driver of normalised strength 0.3 can lead to tipping points occurring at normalised primary driver strengths 0.312 (reduction from baseline: 0.036 [10.3\%]; Figure 2D), and the addition of an extra tertiary driver with normalised strength 0.3 can lead to tipping points at normalised primary strengths 0.270 (reduction from baseline: 0.078 [22.4\%]; Figure 2D). With all additional drivers, $12.3 \%$ of tipping points observed in the Lake Phosphorus model occurred at primary driver strengths below the minimum threshold required to result in a tipping point when the primary driver is acting in isolation (Lake Chilika: 1.2\%; Easter Island: 14.8\%; TRIFFID: 7.7\%; Table S1).

212

213 Next, for each of the four models, the trajectories of the primary slow drivers were randomly 214 perturbed by the addition of noise (Methods Section 2.3). Noise was generated within the system 215 dynamics software used to run the models (STELLA ${ }^{51}$ ) by randomly sampling per timestep from a 216 normal distribution with a mean value of 0 and standard deviation of $\sigma$ (sigma). The value of $\sigma$ was 217 randomly sampled once per simulation to explore the effects of different noise scales on the time to 218 reach the breakpoint date (Methods Section 2.3). Consistent across all models, the addition of low 219 noise (defined as normalised $\sigma$ values $\leq 0.333$ ) at a normalised baseline driver strength of 0.3 has a 220 limited impact upon the breakpoint date, ranging between advancing the date by 4.5 timesteps $(0.5 \%)$ 221 in the Lake Phosphorus model to delaying the breakpoint date by 6.5 years (0.5\%) in the Easter Island 222 model (respective change in the Chilika model: 0 years [0\%]; respective change in the TRIFFID model: 2233 years $[1.2 \%])$. 
However, the addition of high noise (normalised $\sigma$ values $>0.666$ ) highlights that increasing the variability of the primary slow driver (in isolation) across all four models can bring forward the date of system collapse (Figure 3). For example, at a normalised primary driver strength of 0.3 in the Easter Island model (Figure 3B), the addition of high noise brings the median tipping point forward from timestep 1179 to timestep 848 (69.6\% reduction); the same levels of noise at a 0.7 normalised baseline driver strength advance the date of collapse from 663 to 290 (56.4\% reduction). In turn, the equivalent

231 advances in the breakpoints of the other three models under high noise are 11 (34.4\%) and 6 (24.0\%) 232 years for Lake Chilika, 47 (19.7\%) and 18 (16.5\%) years for TRIFFID, and 104 (12.3\%) and 61 (14.5\%) 233 timesteps for Lake Phosphorus, for 0.3 and 0.7 normalised baseline driver strengths respectively. 234 Combined, addition of low, mid and high noise levels resulted in $2.5 \%, 6.6 \%, 2.0 \%$ and $2.6 \%$ of 235 modelled tipping points occurring at primary driver strengths below the minimum threshold required 236 to result in a tipping point when acting in isolation for Lake Chilika, Easter Island, TRIFFID and Lake 237 Phosphorus respectively (Table S2). These results are consistent regardless of whether the noise is coupled to the magnitude of the primary slow driver or not (Figure S2; Table S3).

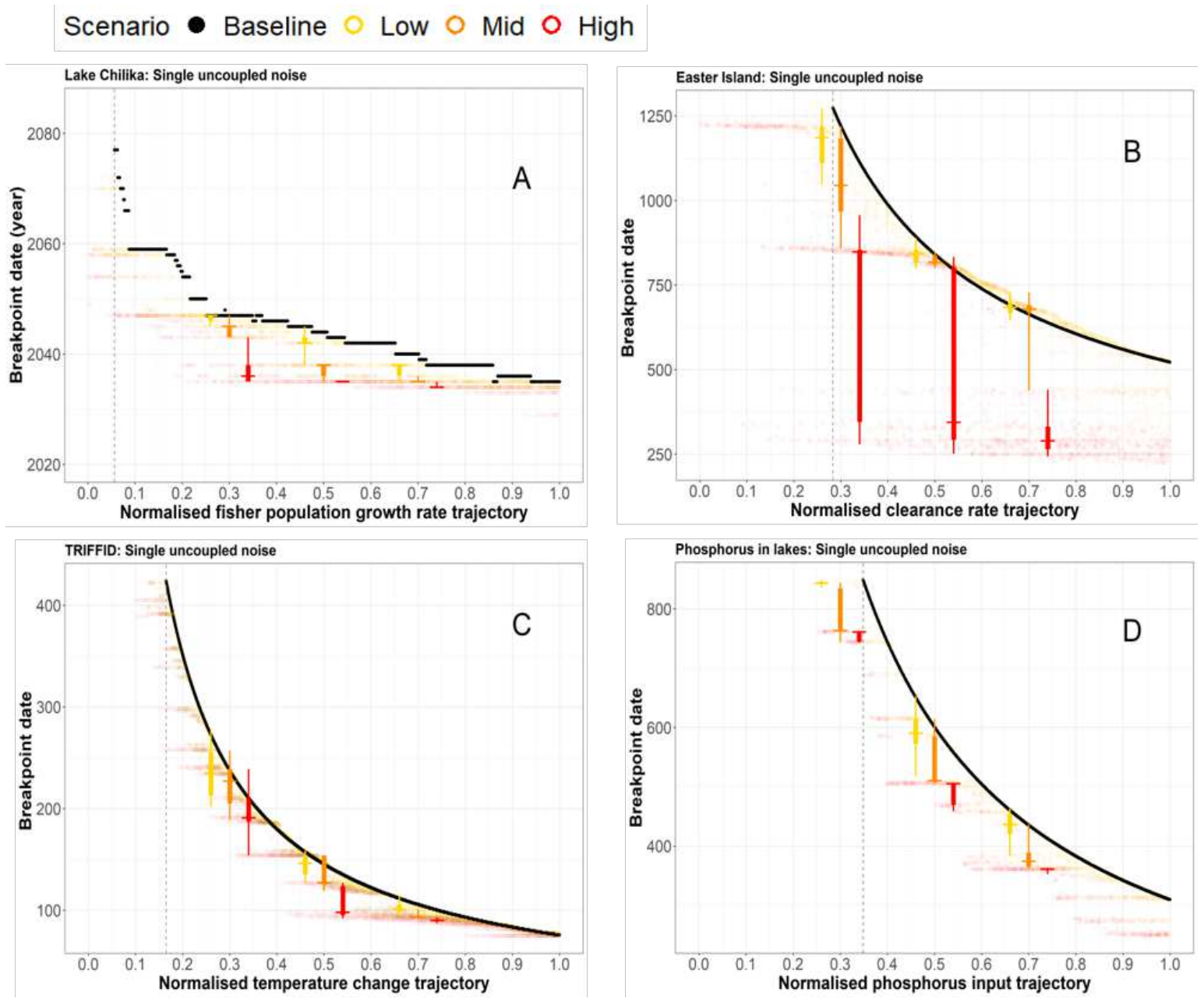


Figure 3 - The relationship between the breakpoint date and the primary slow driver (black; normalised between 0 and 1 ) for varying levels of uncoupled noise in the primary slow driver $(\sigma)$, where normalised $\sigma$ values $\leq 0.333$ signify 'low noise' (yellow), normalised $\sigma$ values $>0.333$ and $\leq$ 0.666 signify 'mid noise' (orange), and normalised $\sigma$ values $>\mathbf{0 . 6 6 6}$ signify 'high noise' (red) (Methods Section 2.3). For each of the noise levels, the boxplots depict the 2.5\%, 25\%, 50\%, 75\% and $97.5 \%$ breakpoint date percentiles, in each of the following ranges along the x-axis: $0.25-0.35,0.45-$ $0.55,0.65-0.75$. Subplots: (A) Chilika model outputs, primary slow driver: fisher population growth; (B) Easter Island model outputs, primary slow driver = tree clearance; (C) TRIFFID model outputs, primary slow driver = temperature change; (D) Lake Phosphorus model outputs, primary slow driver $=$ phosphorus input. The dashed vertical lines denote the minimum primary driver strengths associated with a breakpoint.

253 The effects outlined above are additive, and so combining multiple drivers with noise further reduces

254 the breakpoint date (Figure 4). For example, at a normalised slow baseline driver strength of 0.3 in the Easter Island model (Figure 4B), the addition of low uncoupled noise (normalised $\sigma$ values $\leq 0.333$ ) with all possible additional drivers switched on with normalised strengths of over 0.666 (i.e., 'high' secondary and tertiary trajectories) brings the tipping point forward from timestep 1179 to timestep 426 (58.9\% reduction), whereas high noise levels (defined as normalised $\sigma$ values $>0.666$ ) brings the tipping point forward from timestep 1176 to timestep 225 (80.9\% reduction). The finding that the

260 tipping point date is most advanced by the combination of high noise and high secondary trajectories

261 is consistent across the other three models, with the median tipping point date at a normalised slow

262 baseline driver strength of 0.3 changing from year 2047 to year 2035 (37.5\% reduction) for Lake

263 Chilika, timestep 238 to timestep 92 (61.3\% reduction) for TRIFFID, and timestep 848 to timestep 388

264 (54.2\% reduction) for Lake Phosphorus. Across all combinations of noise and multiple drivers, 1.7\%,

$2657.5 \%, 6.6 \%$ and $8.9 \%$ of modelled tipping points occurred at primary driver strengths below the 266 minimum threshold required to result in a tipping point when acting in isolation for Lake Chilika, Easter 267 Island, TRIFFID and Lake Phosphorus respectively (Table S4). These results are consistent when noise 268 is coupled to the strength of the primary slow driver (Figure S3; Table S5). 

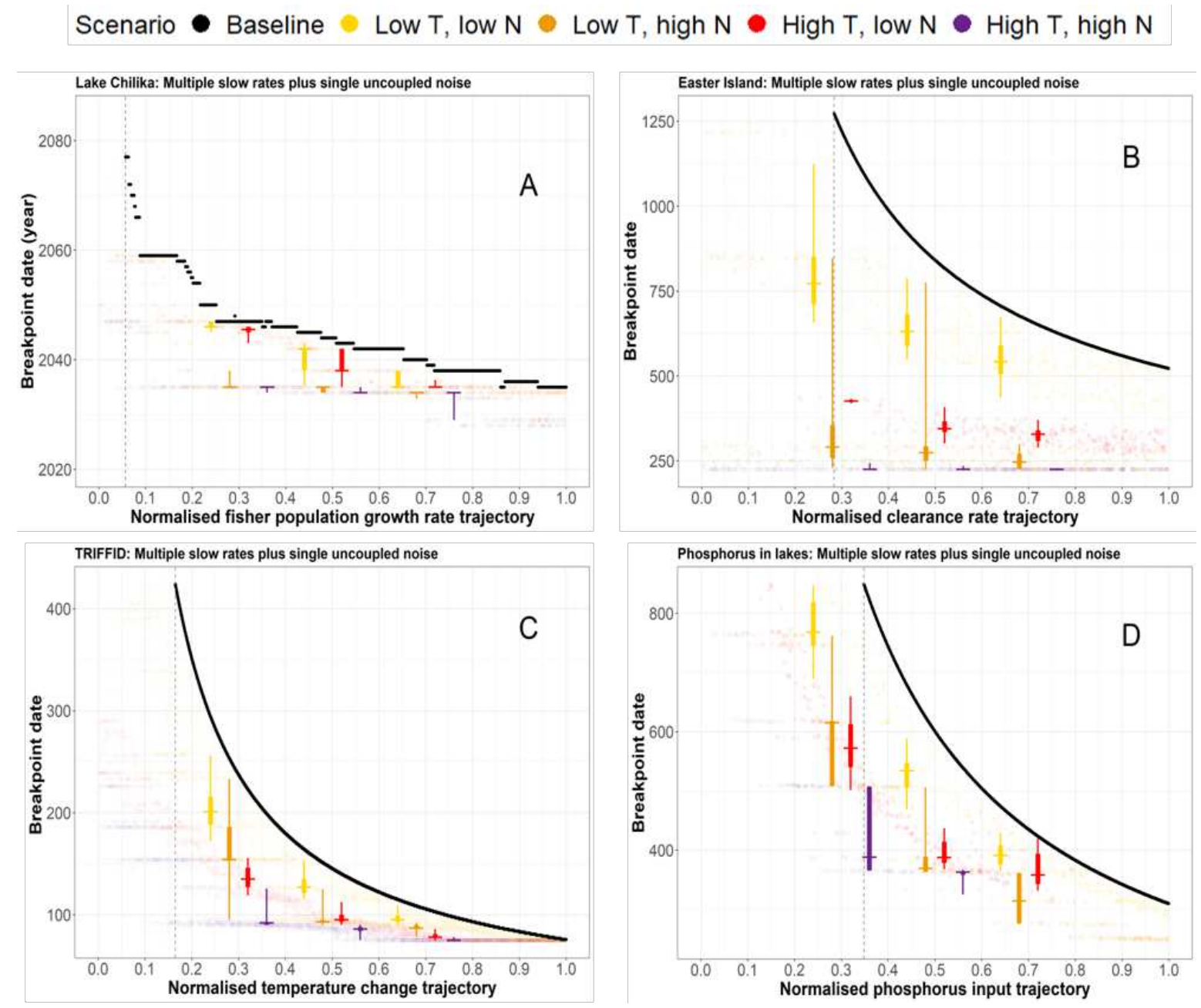

Figure 4 - The relationship between the breakpoint date and the primary slow driver (black; normalised between 0 and 1 ) when weak (normalised T values $\leq 0.333$ ) and strong (normalised $T$ values $>0.666$ ) multiple driver trajectories are combined with weak (normalised $\sigma$ values $\leq \mathbf{0 . 3 3 3}$ ) and strong (normalised $\sigma$ values $>0.666$ ) uncoupled noise ( $T=$ trajectory, $\mathbf{N}=$ noise). For each of the scenarios (i.e. noise and trajectory combinations), the boxplots depict the $2.5 \%, 25 \%, 50 \%, 75 \%$ and $97.5 \%$ breakpoint date percentiles, in each of the following ranges along the $x$-axis: $0.25-0.35,0.45-$ $0.55,0.65-0.75$. Subplots: $(A)$ the Chilika model, primary slow driver $=$ fisher population growth, additional driver: climate change and fish price; (B) the Easter Island model, primary slow driver = tree clearance, additional drivers: agricultural carrying capacity and tree mortality; (C) the TRIFFID model, primary slow driver = temperature change, additional driver: disturbance rate; $(D)$ the lake phosphorus model, primary slow driver = phosphorus, additional drivers: phosphorus recycling rate, phosphorus sedimentation rate. The dashed vertical lines denote the minimum primary driver strengths associated with a breakpoint. Note, the Lake Phosphorus model (subplot D) did not produce any outcomes between the $0.65-0.75$ primary driver range within the 'high trajectory, high noise' scenario; however, the median tipping point date of the adjacent range (0.55-0.65) is 346.

\section{Discussion and conclusions}

288 Previous findings have strongly supported the idea that Earth subsystems may interact to the extent that an abrupt shift in one raises the probability that a shift may occur in another $20,21,52$. In this paper we have explored through four social-ecological models how these interactions may bring forward 
291 the timing of tipping points through the effects of strengthened drivers, multiple drivers and higher 292 internal variability or noise. The potential effects are significant with combinations of strengthened 293 main driver, an additional driver and noise giving at least $38-81 \%$ reductions in the future date of a 294 predicted tipping point compared to estimates for a non-interacting system with a constant single 295 driver and no noise. Importantly, the effect per unit time on bringing forward a tipping point is 296 greatest at low driver trajectories, which further compounds the suggestion that abrupt Earth system 297 changes may occur sooner than we think. Our findings also show that 1.2-14.8\% of tipping points can

298 be triggered by additional drivers and/or noise below the threshold of driver strengths required to 299 collapse the system if only a single driver were in effect.

301 Overall, we find that as the strength of a main driver increases, the systems collapse sooner. Adding 302 multiple drivers further brings forward collapses, as does adding noise, and the two effects can be 303 additive. However, the relative importance of these changes varies across systems. For the Chilika 304 fishery, the most influential driver is captured as the primary driver and so additional drivers have 305 limited influence. However, the addition of noise in the primary driver brings the breakpoint date 306 much further towards the present. For Easter Island, Lake phosphorus, and TRIFFID, the opposite is 307 true - the addition of high levels of noise in the primary driver advances the date of system collapse 308 far less than additional drivers. Thus, while the earliest collapses in all the systems are found when 309 both additional drivers and noise are applied, the precise importance of individual drivers and noise 310 may be system-dependent.

312 These results have research implications for developing and applying tipping point models. Whilst our

313 findings derive from models based on real-world systems, the superior complexity of reality may limit 314 the transferability of our results. For instance, it is plausible that more complex systems will have 315 stronger regulating mechanisms that stabilise the system through sets of balancing feedback loops $\mathrm{s}^{53}$, 316 constraining the more extreme of our findings. Model development is therefore required to better 317 capture the diversity of system elements, interactions and feedbacks for more complex systems. 318 Furthermore, each model in this study was originally created to study the impact of a primary driver, 319 presumably perceived as the most impactful. Our results show that this may not be the case (e.g. 320 Easter Island) and models should include a range of plausible drivers if they are to avoid 321 underestimating the risk of a tipping point. Clearly, new social-ecological models should allow for the 322 growth of feedback loops and long-term simulations in order to observe the mechanisms that 323 underpin a tipping point ${ }^{54,55}$ and the specific changes in system resilience and conditions before and 324 after a tipping point. Similarly, and in support of this model development, monitoring of real world 
systems should capture multiple plausible drivers and their variability. Tipping points will occur unexpectedly if the focus on the perceived main driver ignores other drivers that gradually reduce the resilience of the system, as exemplified in the lake water regime shift at Erhai, western China ${ }^{48}$. There, abrupt lake eutrophication was initially perceived to have been driven by transgression of a threshold in nutrient enrichment driven by agricultural runoff but historical analysis shows that the shift was also affected by lake level management, seasonal climate and fish farming ${ }^{53}$.

332 Predicting tipping points is challenging with most research focusing on identifying early warning 333 metrics linked to critical slowing down theory which applies primarily to system states with single, 334 slow drivers ${ }^{26}$. If, as we suggest, real world tipping elements are more likely to be driven by multiple, 335 fast drivers and extreme events, it is less likely that early warning signals in the frequency domain will 336 be observed, as reported recently by van der Bolt et al..$^{56}$ for fast drivers and Ritchie et al. ${ }^{37}$ for noise 337 induced thresholds. Certainly, excluding noise from model systems risks creating a false sense of 338 security by overestimating the distance remaining before critical thresholds are breached ${ }^{37,57}$. 339 Therefore, alternative approaches to identifying resilience loss in real systems prior to tipping points 340 through structural metrics ${ }^{58-60}$ and early warning signals generated by agent-based models ${ }^{55}$ should 341 be considered more widely.

Previous studies of interactions between tipping elements have focused on large scale systems and suggest significant social and economic costs from the second half of the 21st century onwards ${ }^{52,61}$.

345 Our findings suggest the potential for these costs to occur sooner. For example, it is not clear whether 346 the IPCC's estimate for a tipping point in the Amazon forest prior to $2100^{10}$ includes the possibility for 347 interacting drivers and/or noise: if not, our findings suggest a breakdown may occur several decades 348 earlier. This would occur where local scale failures in elements such as species populations, fish stocks, 349 crop yields and water resources combine with more extreme events such as wildfires and droughts to 350 precondition the large-scale system, already vulnerable to the influence of other large-scale tipping 351 elements, to collapse earlier: a meeting of top-down and bottom-up forces. This vertical integration 352 of forces is reinforced by the rising trend in global warming that already represents a spatial integrator 353 or common driver to many systems, and which may be expected to strengthen before it subsides. 354 Clearly, climate economics need to incorporate these additive and cumulative effects that are occurring at local and regional scales into larger scale models where they are currently lacking ${ }^{62,63}$. The dominance of accelerating trends in global time-series of economic consumption (e.g. ${ }^{7,8}$ ) makes our finding that ramping up the main driver is the easiest way to bring forward a tipping point particularly 
worrying. Similarly, the implication for regions experiencing more extreme events is that a tipping points may occur even before the main driver has ramped up.

The commonality of findings across four well-studied social-ecological systems has potentially profound implications for our perception of future risks associated with the climate and ecological crises. While it is not currently possible to predict how climate-induced tipping points and the effects of local human actions on ecosystems connect across time and spatial scales, our findings show the potential for each to reinforce the other. The ability of present policy and practice to prevent an everdeepening vortex of degradation in local and regional ecosystems requires urgent investigation.

Methods

\section{Overview of systems models}

Here we briefly describe the four previously published models used to investigate the effects of multiple drivers and noise upon the timing of tipping points. Each model was replicated and simulated within the system dynamics software STELLA Architect v.1.6.1 ${ }^{51}$, with outputs exported into CSV files as time series and analysed in the statistical software R v.4.1.064.

The Chilika fishery mode ${ }^{22,44}$ is a social-ecological model designed to simulate the future fish population and catch trajectories of the Chilika lagoon, Odisha, India. The model is able to explore the impacts of multiple slower drivers (i.e. fisher population growth and increased rainfall and temperatures under climate change) and multiple faster drivers (i.e. abrupt changes in fish prices and fishing gear) on the sustainability and resilience of the fish population until 2100 . The model has been previously validated against empirical data through standard behaviour matching techniques and Monte Carlo sensitivity analysis ${ }^{44}$. The Chilika model is run for a total of 1536 timesteps (months), with each timeseries aggregated to the annual scale (c.1973-2100). Future trajectories, detailed in Method Sections 2.2-2.4, activate from timestep 504 (i.e. January 2015) after the completion of the historical parameterisation and validation periods ${ }^{44}$.

The Lake phosphorus model is a simplified version of the original 'lake response to $\mathrm{P}$ input and recycling' model ${ }^{65}$, as modified by Wang et al. ${ }^{48}$. Lake water phosphorus concentration is driven by external phosphorus input. In turn, lake water phosphorus is recycled back into the system as a reinforcing feedback loop, proportional to the lake phosphorus concentration on any given timestep. 
392 Phosphorus is also removed from lake waters via sedimentation, where the volume removed in 393 sediment is proportional to the phosphorus concentration of the lake. Therefore, on any given 394 timestep, the change in lake phosphorus concentration ( $\mathrm{dP} / \mathrm{dt}$ ) equals:

$$
d P=\left[a-s P+r \frac{P^{n}}{P^{n}+1^{n}}\right] d t
$$

Where $P$ is phosphorus concentration, $\alpha$ is phosphorus input rate (Methods Section 2.3), $r$ is the maximum recycling rate (Methods Section 2.4), $s$ is the phosphorus loss rate (Methods Section 2.4), $n$ is the strength of the recycling response to phosphorus concentrations $(n=8)$ and $t$ is time. The model is run for 1000 timesteps (unitless), with future scenarios active from the first timestep (Method Sections 2.2-2.4).

The Easter Island model aims to explore alternative hypotheses behind the social-ecological collapse of the Easter Island civilisation ${ }^{49}$. The main feedback driving model dynamics is the balancing feedback between human population growth, tree coverage and land clearance, whereby the overharvesting of the primary resource (palm forest) can lead to overshoot dynamics and the eventual demise of the human population. Multiple external variables can be modified to change the speed of human population growth, including the tree clearance rate per capita, the maximum carrying capacity of the agricultural system (i.e. to help support human population growth), and the mortality rate of trees (i.e. representative of potential disease outbreaks). The model is run for 1500 timesteps (years), with future scenarios active from the first timestep (Method Sections 2.2-2.4).

The TRIFFID model is a modified version of The Hadley Centre Dynamic Global Vegetation Model, 413 originally developed by Cox et $a .^{50}$ to explore the effects of atmospheric $\mathrm{CO}_{2}$ concentrations on the 414 rate of Amazon dieback. Here we simulate the modified version developed by Ritchie et al. ${ }^{37}$, which is 415 based around a central Lotka-Volterra equation describing the change in vegetation coverage as local 416 atmospheric temperatures increase. On any given timestep, the change in vegetation coverage ( $d v / d t)$ 417 is driven by a temperature dependent growth term and an externally set disturbance rate:

$$
\begin{aligned}
& \frac{d v}{d t}=g v(1-v)-y v \\
& g=g_{0}\left[1-\left(\frac{T_{i}-T_{o p t}}{\beta}\right)^{2}\right]
\end{aligned}
$$$$
\text { (Equation 2a) }
$$

$$
T_{l}=T_{f}+(1-v) \alpha
$$

421 Where $v$ is the vegetation coverage, $\mathrm{T}_{\mathrm{f}}$ is the temperature forcing parameter (Methods Section 2.3), $g$ 422 is the vegetation growth rate, $g_{0}$ is the maximum growth rate (2/year), $y$ is the disturbance rate 423 (Methods Section 2.4), $T$, is the local temperature, $T_{\text {opt }}$ is the optimal temperature $\left(28^{\circ} \mathrm{C}\right), B$ is the half424 width of the growth versus temperature curve $\left(10^{\circ} \mathrm{C}\right)$ and $\alpha$ is the difference in temperature between 
surface bare soil and forest $\left(5^{\circ} \mathrm{C}\right)$. Therefore, the growth term is assumed to be parabolic with the local temperature (Equation $2 \mathrm{~b}$ ), meaning that once the local temperature increases beyond the optimal temperature, negative tree growth ensues (i.e. additional tree mortality) ${ }^{37}$. In turn, a decline in vegetation leads to an increase in temperature (Equation $2 \mathrm{c}$ ), which may eventually produce the runaway loss in tree coverage. The model is run for 500 timesteps, with future trajectories active from the first timestep (Method Sections 2.2-2.4).

\section{Generation of future scenarios}

Using the above models, we performed four in silico experiments (presented visually in Figure 1):

- Experiment \#1: only the primary slow driver in each model changes over time, and all other drivers remain constant (Figure 2 baseline);

- Experiment \#2: multiple slow rates, with up to two additional (i.e. 'secondary' and 'tertiary') slow trajectories on top of the primary driver changing over time (Figure 2 multiple drivers);

- Experiment \#3: the addition of noise to the primary trajectory (Figure 3), with all other drivers held constant. The magnitude of noise may be either coupled or uncoupled from the trajectory of the primary driver (Methods Section 2.3);

- Experiment \#4: the addition of noise to the primary driver, with up to two additional slow drivers (Figure 4). The magnitude of noise may be either coupled or uncoupled from the trajectory of the primary driver (Methods Section 2.3).

In order to survey a wide range of future trajectories (Methods Sections 2.2) and generate a sufficient number of simulations that tipped (Methods Section 3), each of the models were ran for the following number of iterations (including both 'coupled' and 'uncoupled' settings):

- Chilika fishery: 70,000

- Easter Island: 70,000

- TRIFID: 70,000

In turn, to maximise computational efficiency both in STELLA and in R, the following logic was applied to the in-built Monte Carlo function in STELLA to automatically generate the four different experiment types described above (the baseline primary driver always remains 'on/active'): 
Where $\mu_{1}, \mu_{2}$ and $\mu_{3}$ represent 'on switches', with values randomly sampled from uniform distributions between 0 and 1 per simulation. The number of simulations per model experiment which successfully tipped are detailed in Table $\mathbf{S 6}$.

\subsection{Experiment 1: Primary scenario trajectories}

In order to investigate Experiment 1(, each of the four models have one primary baseline driver which changes from its default value in every simulation:

- Chilika fishery: Fisher population growth rate (net difference between the birth rate per 1000 population and the death rate per 1000 population)

- Easter Island: Tree clearance rate (trees/person/year)

- Lake phosphorus: Phosphorus input rate (unitless)

- TRIFFID: local temperature $\left({ }^{\circ} \mathrm{C}\right)$

Baseline outputs were generated with the Primary driver active AND the Secondary and Tertiary driver remaining at its default value AND the Noise level remaining at zero (Table S7). In turn, the Monte Carlo sensitivity analysis function in STELLA randomly samples a future change trajectory for the primary slow driver per simulation (as plotted on the horizontal axes of Figures 2-4). The primary trajectory is sampled between the lower and upper limits of uniform distribution bounds, meaning that there is a uniform likelihood of selecting any given trajectory between the bounds (Table S7). A future change trajectory of ' 0 ' would cause no change from the default value; the maximum trajectory change limits for each of the models can be seen in Table S7.

The built-in STELLA 'TIME' function generates future scenario trajectories that change linearly over time (i.e. with a constant gradient over the model horizon). Therefore, the value of the primary driver at any given timestep equals:

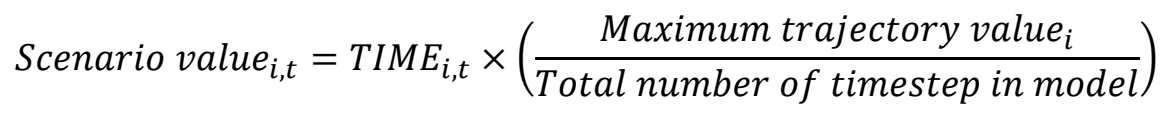

Where ' $i$ ' equals the simulation number and ' $t$ ' equals the timestep (e.g. $t=1,2,3 \ldots$ total number of timesteps in model). Using the Easter Island model as an example: if a maximum tree clearance value of 7 has been sampled for the given simulation, then its value after 500 timesteps would be equal to $500 \times(7 / 1500)=2.333$. The plausible trajectory funnels for each of the primary drivers are plotted in Figure S4.

489 To simulate Experiment 2, 'secondary' and 'tertiary' driver trajectories are also activated using the 490 following logic: 
- 'Secondary': Primary driver active AND Secondary driver active AND Tertiary driver remains at default value AND Noise level remains at zero OR

- 'Tertiary': Primary driver active AND Secondary driver remains at default value AND Tertiary driver active AND Noise level remains at zero OR

- 'All': Primary driver active AND Secondary driver active AND Tertiary driver active AND Noise level remains at zero

For each model, this specifically involved the following variables (Table S7):

- Chilika fishery: (1) Annual rainfall totals and mean near-surface air temperatures, as per IPCC (2013) climate change projections for the east coast of India (2) Price of fish per unit (i.e. Indian rupee $/ \mathrm{kg}$ ), leading to a more commercially-oriented fishery, with an increasing number of fishers able to upgrade from traditional fishing boats to more intensive motorboats ${ }^{44}$.

- Easter Island: (1) Agricultural carrying capacity of the system, which enables a higher human population to be supported per unit of land cleared for agriculture; (2) The mortality rate of trees as a proxy for a disease-spread event.

- Lake Phosphorus: (1) Rate of phosphorus recycling within the lake environment, (2) Rate of phosphorus removal from the lake via sedimentation.

- TRIFFID: (1) Temperature-independent disturbance rate of vegetation coverage, i.e. causes of forest clearance which are not directly linked to temperature changes (e.g. deforestation). Note: Due to the small size of the model, TRIFFID does not have a tertiary driver.

From here, each of the additional driver trajectories are produced via the same approach as in Equation 3: the Monte Carlo sensitivity analysis function in STELLA randomly samples a trajectory between the lower and upper bounds of a uniform distribution for each driver (Table S7); in turn, the TIME function linearly increases the value of the driver from its default value to its sampled trajectory value by the final timestep of the model horizon.

In order to produce one secondary trajectory per simulation in the Chilika model, the sampling of rainfall and temperature trajectories are connected along a linear gradient, ranging from no change to a combination of $+30 \%$ rainfall change and $+4.5^{\circ} \mathrm{C}$ temperature change by $2081-2100$ relative to 1986-2005 (as per RCP8.5 projections for the east coast of India ${ }^{66}$ ). In STELLA, this is operationalised by the model variable 'climate change trend', with Monte Carlo sensitivity analysis in STELLA randomly sampling a value between 0 and 1 per simulation. As an illustration, if a value of 0.6 was to be sampled, then the change in rainfall by $2081-2100$ (relative to $1986-2005$ ) would equal $0.6 * 30(\%)=18 \%$, whilst the change in temperature would equal $0.6 * 4.5\left({ }^{\circ} \mathrm{C}\right)=2.7^{\circ} \mathrm{C}$. 
526 In order to investigate Experiment \#3 and Experiment \#4, the value of each primary slow driver is 527 perturbed per timestep by randomly generated noise. We simulate a standard Wiener process to 528 generate noise, equal to $\sqrt{d t} \times N(0,1)$, where ' $\mathrm{dt}^{\prime}$ ' equals change in time and ' $N(0,1)$ ' is a normal 529 distribution with a mean of 0 and standard deviation of one. In turn, the product of the Wiener process

530 is multiplied by the scaling factor 'sigma' $(\sigma)$, providing an overall level of noise to be added to the 531 value of the primary driver on any given timestep. As per the future trajectories, the magnitude of ' $\sigma$ ' 532 is randomly sampled once per simulation from uniform distributions, with lower and upper limits 533 shown in Table S7.

534 Therefore, building on Equation 3 above, the value of a primary driver at any point in time in Experiment \#3 and Experiment \#4 equal:

Scenario value $_{i, t}=\operatorname{TIME}_{i, t} \times\left(\frac{\text { Maximum trajectory value }}{i}\right)+\left(\sigma_{i} \times \sqrt{d t} \times N(0,1)_{t}\right)$

Equation 4 as detailed above only refers to the 'uncoupled' noise simulations. Therefore, to explore the effects of 'coupled' noise, whereby the magnitude of noise increases with the growth in the primary driver, 20,000 simulations were run per model spread evenly between Experiments \#3 and $\# 4$, with the magnitude of noise coupled to the magnitude of the primary driver trajectory. Given the differences in the shape of the noise spectrums, we do not directly compare outcomes from the uncoupled and coupled noise simulations in this study. Instead, the purpose of modelling coupled noise is to ascertain whether worsening magnitudes of extreme events over time are associated with earlier tipping points. In the coupled simulations, Equation 4 is modified to:

Scenario value $_{i, t}$

$$
\begin{aligned}
& =\operatorname{TIME}_{i, t} \times\left(\frac{\left.{\text { Maximum trajectory } \text { value }_{i}}_{\text {Total number of timestep in model }}\right)}{+\left(\sigma_{i} \times \sqrt{d t} \times N(0,1)_{t} \times\right. \text { Change in Scenario value from default }}{ }_{i, t}\right)
\end{aligned}
$$

For experiment 3 (single slow driver plus noise), the runs were generated in STELLA ${ }^{51}$ with the following logic: Primary driver active AND Secondary driver remains at default value AND Tertiary driver remains at default value AND Noise active. For experiment 4 (noise plus multiple slow drivers), the logic used included: 
- Primary driver active AND Secondary driver remains at default value AND Tertiary driver active AND Noise active

- Primary driver active AND Secondary driver active AND Tertiary driver active AND Noise active

\section{Timeseries breakpoint detection}

The identification of the timing of the tipping point in the model runs was a two-step process. First, to ensure that we were only analysing model runs that had transitioned (i.e. collapsed) to quantitatively and qualitatively different states (e.g. fishery collapse, civilisation collapse, lake eutrophication or forest dieback), we assessed whether model outcomes had crossed a pre-defined threshold at any point over the model horizon. For the three models which observe collapses in the outcome variable (i.e. Chilika fishery, Easter Island and TRIFFID), model runs were considered to have reached a collapsed state if the outcome variable reached a value beneath $20 \%$ of its initial value at any point during the simulation. This demarcation is therefore representative of Type-1 boundaries defined by Dearing et al. ${ }^{14}$, with the numerical value of the boundary in line with the concept that fish stocks may be considered collapsed once their biomass falls beneath $20 \%$ of the biomass needed to maintain maximum sustainable yield ${ }^{67,68}$. In the case of the Chilika fishery model, which has inbuilt socialecological feedbacks that may trigger the recovery and later re-collapse of the fishery ${ }^{22,44}$, we subset the timeseries to the period prior to the first timestep beneath $20 \%$ of the initial fish population. As we are only interested in the initial collapse, not sub-setting this time period would risk capturing subsequent collapses and recoveries in the analysis.

With lake eutrophication caused by an increase in phosphorus concentrations, a linear threshold beyond which we could be confident that the model had entered a qualitatively different state could not be identified. Therefore, as per the approach taken by Drijfhout et al. ${ }^{38}$ for identifying abrupt events in global climate models, we adopted a Dearing et al. ${ }^{14}$ Type-2 boundary to include only simulations which reached lake phosphorus concentrations greater than four times the standard deviation (SD) of the pre-tipping point time series. Therefore, runs of the Lake Phosphorus model which did not exceed this 4xSD threshold were not considered to reach phosphorus concentrations sufficiently outside of the pre-transition envelope of variability, and were therefore excluded from our analysis. 
592 The optimal breakpoint function of the R package 'strucchange' v.1.5-2 ${ }^{69}$ then identified tipping point

593 dates in the time series that had successfully met the above qualifications (i.e. reached an alternative

594 state). As described in Cooper et al. ${ }^{70}$, the optimal breakpoint function finds the most significant

595 deviation from stability in classical regression models, whereby regressions coefficients shift from one

596 stable regime to another. Therefore, the breakpoint date is taken as the most significant deviation of

597 the outcome variable en route to its qualitatively and quantitatively alternative state.

\section{Boxplots and output graphs}

600 For each of the experiments (i.e. Methods Sections 2.1-2.3), boxplots were generated to visualise the 601 distribution of tipping point dates for each of the slow driver and noise level combinations (Figures 2-

602 4). To standardise the comparisons between experiments, the normalised magnitude $(0 \rightarrow 1)$ of the 603 primary trajectories (Table S7) for each model was plotted on the horizontal axes. In turn, to visualise 604 how the breakpoint dates change with the addition of secondary or noisy stresses over the range of 605 the primary trajectories, model outcomes that tipped (Methods Sections 3.1-3.2) were subset in the 606 statistical software $R$ between normalised primary trajectory values of $0.25-0.35,0.45-0.55$, and 0.65 607 0.75. From here, for each of the driver combinations (e.g. 'primary only', 'primary and secondary', 608 etc.) and primary driver subsets (e.g. $0.25-0.35,0.45-0.55$ etc.), boxplots depicting the $2.5 \%, 25 \%, 50 \%$, $60975 \%$ and $97.5 \%$ breakpoint date percentiles were graphed in R using the package 'ggplot' (v.3.3.5) ${ }^{71}$.

610

\section{Acknowledgments}

612 SW received funding by NE/T00391X/1, ES/T007877/1, ES/R009279/1, and AH/W003813/1. GSC 613 received funding by the UKRI-GCRF Action Against Stunting Hub (Project ref. MR/S01313X/1). The 614 views expressed in this work are those of the creators and do not necessarily represent those of Global 615 Challenges Research Fund or UK Research and Innovation.

616

\section{Author Contributions}

618 JAD, SW \& GSC conceived the project. GSC ran the computer models, with JA conducting the analysis. 619 SW, JAD \& GSC wrote the manuscript, with comments from JA.

622 1. Beddington, J. Food, Energy, Water and the Climate: A Perfect Storm of global events. (2009).

623 2. Bradshaw, C. J. A. et al. Underestimating the Challenges of Avoiding a Ghastly Future. Front. Conserv. Sci. 0, 9 (2021).

3. Retsa, A., Schelske, O., Wilke, B., Rutherford, G. \& de Jong, R. Biodiversity and Ecosystem Services A business case for re/insurance. https://www.swissre.com/institute/research/topicsand-risk-dialogues/climate-and-natural-catastrophe-risk/expertise-publication-biodiversityand-ecosystems-services (2020). 
629 4. Reichstein, M., Riede, F. \& Frank, D. More floods, fires and cyclones - plan for domino effects

$630 \quad$ on sustainability goals. Nat. 20215927854 592, 347-349 (2021).

631 5. Scheffer, M. et al. Anticipating Critical Transitions. Science (80-. ). 338, 344-348 (2012).

632 6. Kareiva, P. \& Carranza, V. Existential risk due to ecosystem collapse: Nature strikes back.

633 Futures 102, 39-50 (2018).

634 7. Steffen, W., Broadgate, W., Deutsch, L., Gaffney, O. \& Ludwig, C. The trajectory of the Anthropocene: The Great Acceleration: Anthr. Rev. 2, 81-98 (2015).

8. Ripple, W. J., Wolf, C., Newsome, T. M., Barnard, P. \& Moomaw, W. R. World Scientists' Warning of a Climate Emergency. Bioscience 70, 8-12 (2020).

9. Lenton, T. M. et al. Tipping elements in the Earth's climate system. Proc. Natl. Acad. Sci. U. S. A. 105, 1786-93 (2008).

10. IPCC. Summary for Policymakers. in Climate Change 2021: The Physical Science Basis. Contribution of Working Group I to the Sixth Assessment Report of the Intergovernmental Panel on Climate Change (eds. Masson-Delmotte et al.) 1-3949 (Cambridge University Press, 2021).

11. Barnosky, A. D. et al. Approaching a state shift in Earth's biosphere. Nat. 20124867401 486, 52-58 (2012).

12. Hughes, T. P., Carpenter, S., Rockström, J., Scheffer, M. \& Walker, B. Multiscale regime shifts and planetary boundaries. Trends Ecol. Evol. 28, 389-395 (2013).

13. Biggs, R., Peterson, G. D. \& Rocha, J. C. The Regime Shifts Database: a framework for analyzing regime shifts in social-ecological systems. Ecol. Soc. Publ. online Jul 19, 2018 / doi10.5751/ES10264-230309 23, (2018).

14. Dearing, J. A. et al. Safe and just operating spaces for regional social-ecological systems. Glob. Environ. Chang. 28, 227-238 (2014).

15. Rockström, J. et al. A safe operating space for humanity. Nature 461, 472-5 (2009).

16. Trenberth, K. E., Fasullo, J. T. \& Shepherd, T. G. Attribution of climate extreme events. Nat. Clim. Chang. 201558 5, 725-730 (2015).

17. Trenberth, K. E. et al. Global warming and changes in drought. Nat. Clim. Chang. 201441 4, 17-22 (2013).

18. Wunderling, N., Donges, J. F., Kurths, J. \& Winkelmann, R. Interacting tipping elements increase risk of climate domino effects under global warming. Earth Syst. Dyn. 12, 601-619 (2021).

19. Kriegler, E., Hall, J. W., Held, H., Dawson, R. \& Schellnhuber, H. J. Imprecise probability assessment of tipping points in the climate system. Proc. Natl. Acad. Sci. 106, 5041-5046 (2009).

20. Klose, A. K., Karle, V., Winkelmann, R. \& Donges, J. F. Emergence of cascading dynamics in interacting tipping elements of ecology and climate. R. Soc. Open Sci. 7, 200599 (2020).

21. Krönke, J. et al. Dynamics of tipping cascades on complex networks. Phys. Rev. E 101, 042311 (2020).

22. Cooper, G. S., Willcock, S. \& Dearing, J. A. Regime shifts occur disproportionately faster in larger ecosystems. Nat. Commun. 2020111 11, 1-10 (2020).

23. Rocha, J. C., Peterson, G., Bodin, Ö. \& Levin, S. Cascading regime shifts within and across scales. Science (80-. ). 362, 1379-1383 (2018).

24. Lade, S. J. et al. Human impacts on planetary boundaries amplified by Earth system interactions. Nat. Sustain. 201932 3, 119-128 (2019).

25. Brown, C. \& Rounsevell, M. How can social-ecological system models simulate the emergence of social-ecological crises? People Nat. 3, 88-103 (2021).

26. Scheffer, M. et al. Early-warning signals for critical transitions. Nature 461, 53-9 (2009).

27. Ashwin, P., Wieczorek, S., Vitolo, R. \& Cox, P. Tipping points in open systems: bifurcation, noiseinduced and rate-dependent examples in the climate system. Philos. Trans. R. Soc. A Math. Phys. Eng. Sci. 370, 1166-1184 (2012).

28. Thompson, R. M., Beardall, J., Beringer, J., Grace, M. \& Sardina, P. Means and extremes: building variability into community-level climate change experiments. Ecol. Lett. 16, 799-806 
680

681

682

683

684

685

686

687

688

689

690

691

692

693

694

695

696

697

698

699

700

701

702

703

704

705

706

707

708

709

710

711

712

713

714

715

716

717

718

719

720

721

722

723

724

725

726

727

728

729

730

(2013).

29. Kreyling, J., Jentsch, A. \& Beier, C. Beyond realism in climate change experiments: gradient approaches identify thresholds and tipping points. Ecol. Lett. 17, 125-e1 (2014).

30. Steffen, W. et al. Planetary boundaries: Guiding human development on a changing planet. Science (80-. ). 347, (2015).

31. Secretariat of the Convention on Biological Diversity. Global Biodiversity Outlook 5. www.cbd.int/GBO5 (2020).

32. Büntgen, U. et al. Recent European drought extremes beyond Common Era background variability. Nat. Geosci. 2021144 14, 190-196 (2021).

33. Abram, N. J. et al. Connections of climate change and variability to large and extreme forest fires in southeast Australia. Commun. Earth Environ. 2021 21 2, 1-17 (2021).

34. Toreti, A., Cronie, O. \& Zampieri, M. Concurrent climate extremes in the key wheat producing regions of the world. Sci. Reports 201991 9, 1-8 (2019).

35. Vogel, M. M., Hauser, M. \& Seneviratne, S. I. Projected changes in hot, dry and wet extreme events' clusters in CMIP6 multi-model ensemble. Environ. Res. Lett. 15, 094021 (2020).

36. Gaupp, F., Hall, J., Mitchell, D. \& Dadson, S. Increasing risks of multiple breadbasket failure under 1.5 and $2{ }^{\circ} \mathrm{C}$ global warming. Agric. Syst. 175, 34-45 (2019).

37. Ritchie, P. D. L., Clarke, J. J., Cox, P. M. \& Huntingford, C. Overshooting tipping point thresholds in a changing climate. Nat. 20215927855 592, 517-523 (2021).

38. Drijfhout, S. et al. Catalogue of abrupt shifts in Intergovernmental Panel on Climate Change climate models. Proc. Natl. Acad. Sci. U. S. A. 112, E5777-E5786 (2015).

39. Steffen, W. et al. Trajectories of the Earth System in the Anthropocene. Proc. Natl. Acad. Sci. U. S. A. 115, 8252-8259 (2018).

40. Hubau, W. et al. Asynchronous carbon sink saturation in African and Amazonian tropical forests. Nature 579, 80-87 (2020).

41. Duffy, K. A. et al. How close are we to the temperature tipping point of the terrestrial biosphere? Sci. Adv. 7, (2021).

42. Kelly, R. A. et al. Selecting among five common modelling approaches for integrated environmental assessment and management. Environ. Model. Softw. 47, 159-181 (2013).

43. Filatova, T., Polhill, J. G. \& van Ewijk, S. Regime shifts in coupled socio-environmental systems: Review of modelling challenges and approaches. Environ. Model. Softw. 75, 333-347 (2016).

44. Cooper, G. S. \& Dearing, J. A. Modelling future safe and just operating spaces in regional socialecological systems. Sci. Total Environ. 651, 2105-2117 (2019).

45. Tenza, A., Pérez, I., Martínez-Fernández, J. \& Giménez, A. Understanding the decline and resilience loss of a long-lived social-ecological system: insights from system dynamics. Ecol. Soc. Publ. online May 02, 2017 / doi10.5751/ES-09176-220215 22, (2017).

46. Martin, R. \& Schlüter, M. Combining system dynamics and agent-based modeling to analyze social-ecological interactions-an example from modeling restoration of a shallow lake. Front. Environ. Sci. 3, 66 (2015).

47. Carpenter, S. R., Ludwig, D. \& Brock, W. A. Management of eutrophication for lakes subject to potentially irreversible change. Ecol. Appl. 9, 751-771 (1999).

48. Wang, R. et al. Flickering gives early warning signals of a critical transition to a eutrophic lake state. Nature 492, 419-22 (2012).

49. Brandt, G. \& Merico, A. The slow demise of Easter Island: Insights from a modeling investigation. Front. Ecol. Evol. 3, 13 (2015).

50. Cox, P. M. et al. Amazonian forest dieback under climate-carbon cycle projections for the 21st century. Theor. Appl. Climatol. 2004781 78, 137-156 (2004).

51. ISEE Systems. STELLA Architect: Systems Thinking for Education and Research. (2018).

52. Kinzig, A. P. et al. Resilience and regime shifts: assessing cascading effects. Ecol. Soc. 11, 1-23 (2006).

53. Wang, R., Dearing, J. A. \& Langdon, P. G. Critical transitions in ecosystem state are driven by 
coupled feedback mechanisms: a case study from Erhai lake, China. Water 13, (2021).

54. Verburg, P. H. et al. Methods and approaches to modelling the Anthropocene. Glob. Environ. Chang. 39, 328-340 (2016).

55. Reisinger, D. \& Füllsack, M. Comparing Equation-Based and Agent-Based Data Generation Methods for Early Warning Signal Analysis. Syst. 2020, Vol. 8, Page 54 8, 54 (2020).

56. Van Der Bolt, B., Van Nes, E. H. \& Scheffer, M. No warning for slow transitions. J. R. Soc. Interface 18, (2021).

57. Bury, T. M. et al. Deep learning for early warning signals of tipping points. Proc. Natl. Acad. Sci. U. S. A. 118, (2021).

58. Doncaster, C. P. et al. Early warning of critical transitions in biodiversity from compositional disorder. Ecology 97, 3079-3090 (2016).

59. Wang, R. et al. Network parameters quantify loss of assemblage structure in human-impacted lake ecosystems. Glob. Chang. Biol. 25, 3871-3882 (2019).

60. Mayfield, R. J. et al. Metrics of structural change as indicators of chironomid community stability in high latitude lakes. Quat. Sci. Rev. 249, 106594 (2020).

61. Cai, Y., Lenton, T. M. \& Lontzek, T. S. Risk of multiple interacting tipping points should encourage rapid CO2 emission reduction. Nat. Clim. Chang. 201665 6, 520-525 (2016).

62. Dietz, S., Rising, J., Stoerk, T. \& Wagner, G. Economic impacts of tipping points in the climate system. Proc. Natl. Acad. Sci. U. S. A. 118, (2021).

63. Fabbri, S., Hauschild, M. Z., Lenton, T. M. \& Owsianiak, M. Multiple climate tipping points metrics for improved sustainability assessment of products and services. Environ. Sci. Technol. 55, 2800-2810 (2021).

64. R Core Team. R: A language and environment for statistical computing. (2020).

65. Carpenter, S. R., Ludwig, D. \& Brock, W. A. Management of Eutrophication for Lakes Subject to Potentially Irreversible Change. Ecol. Appl. 9, 751-771 (1999).

66. IPCC. Climate Change 2013: The Physical Science Basis. in Contribution of Working Group I to the Fifth Assessment Report of the Intergovernmental Panel on Climate Change (eds. Stocker, T. F. et al.) 1535 (Cambridge University Press, 2013).

67. Worm, B. et al. Rebuilding Global Fisheries. Science (80-. ). 325, 578-585 (2009).

68. Pinsky, M. L., Jensen, O. P., Ricard, D. \& Palumbi, S. R. Unexpected patterns of fisheries collapse in the world's oceans. Proc. Natl. Acad. Sci. U. S. A. 108, 8317-8322 (2011).

69. Zeileis, A., Leisch, F., Hornik, K. \& Kleiber, C. Package "strucchange". https://cran.rproject.org/web/packages/strucchange/strucchange.pdf (2015).

70. Cooper, G. S., Willcock, S. \& Dearing, J. A. Regime shifts occur disproportionately faster in larger ecosystems. Nat. Commun. 11, 1175 (2020).

71. Wickham, H. ggplot2: Elegant Graphics for Data Analysis. (2016) doi:978-3-319-24277-4. 
770
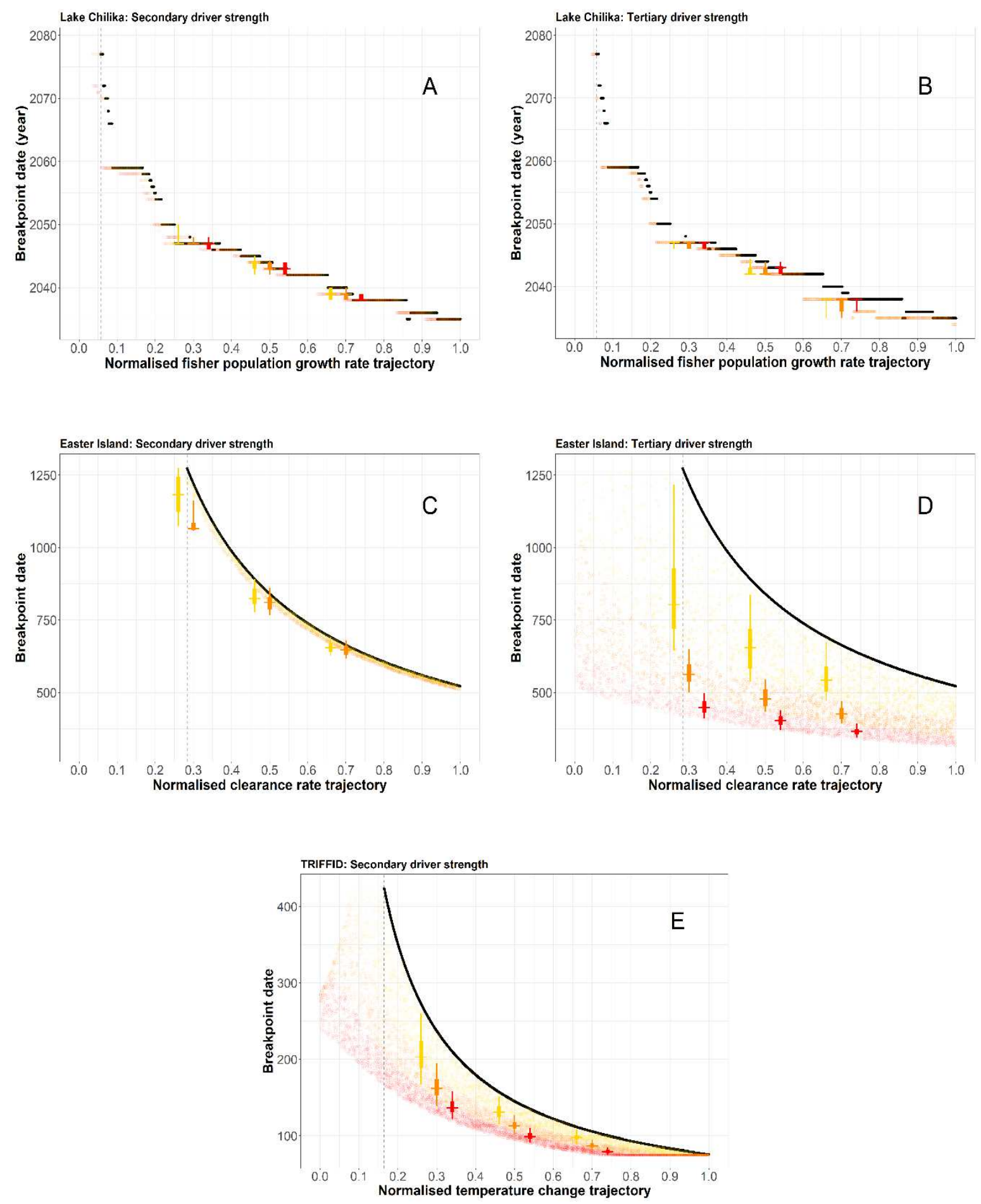

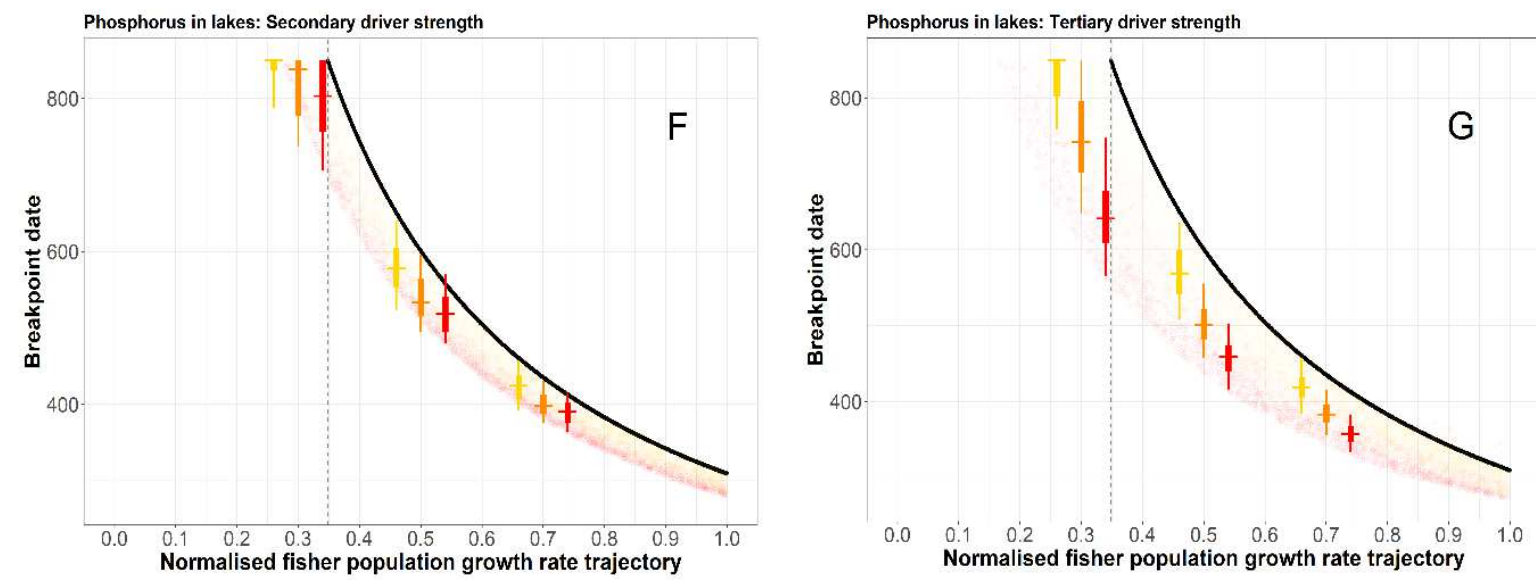

Figure S1 - The distribution of breakpoint dates along the range of primary slow driver trajectories (black; normalised between 0 and 1 ) in each of the models, with the additional effects of the secondary and tertiary drivers in each model disaggregated. The left column shows the combined effects of the primary plus secondary drivers in each model, and the right column shows the combined effects of the primary plus tertiary drivers in each model. For each of the scenarios (i.e. driver combinations), the boxplots depict the $2.5 \%, 25 \%, 50 \%, 75 \%$ and $97.5 \%$ breakpoint date percentiles, in each of the following ranges along the $\mathrm{x}$-axis: $0.25-0.35,0.45-0.55,0.65-0.75$. The dashed vertical lines denote the minimum primary driver strengths associated with a breakpoint. Subplots: (A) Chilika model, primary slow driver: fisher population growth, secondary driver: climate change, tertiary driver: fish price; (B) Easter Island model, primary slow driver = tree clearance, secondary driver: agricultural carrying capacity, tertiary driver: tree mortality; (C) TRIFFID model, primary slow driver: temperature change, secondary driver: disturbance rate; (D) Lake phosphorus model, primary slow driver: phosphorus external input, secondary driver: phosphorus recycling rate, tertiary driver: phosphorus sedimentation rate. The dashed vertical lines denote the minimum primary driver strength associated with a breakpoint. 

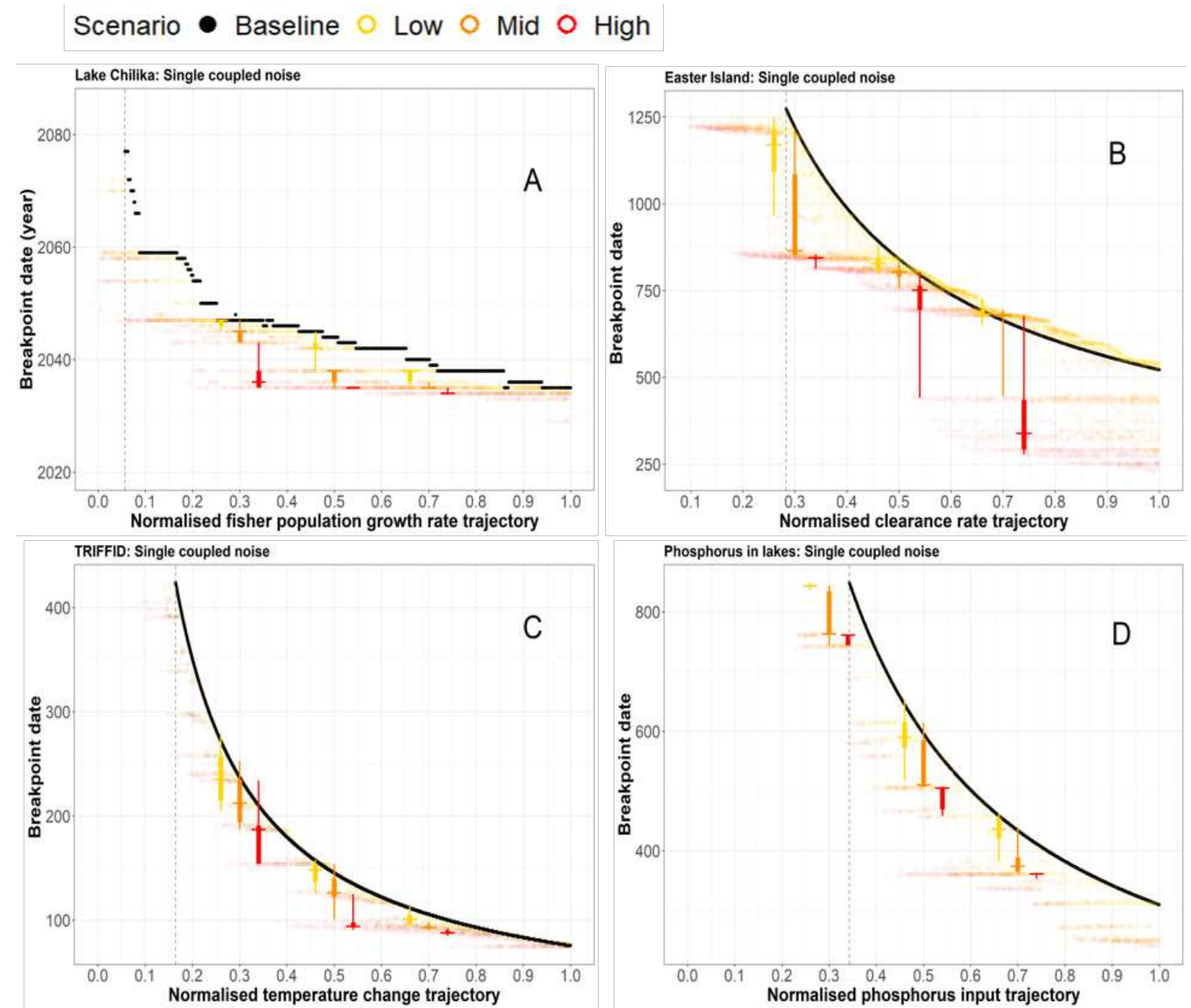

787 Figure S2 - The relationship between the breakpoint date and the primary slow driver (black;

788 normalised between $\mathbf{0}$ and 1 ) for varying levels of coupled noise in the primary driver $(\sigma)$, where

789 normalised $\sigma$ values $\leq 0.333$ signify 'low noise' (yellow), normalised $\sigma$ values $>0.333$ and $\leq 0.666$ signify 'mid noise' (orange), and normalised $\sigma$ values $>0.666$ signify 'high noise' (red) (Methods Section 2.3). Subplots: For each of the noise levels, the boxplots depict the $2.5 \%, 25 \%, 50 \%, 75 \%$ and $97.5 \%$ breakpoint date percentiles, in each of the following ranges along the $x$-axis: $0.25-0.35,0.45-$ $0.55,0.65-0.75$. The dashed vertical lines denote the minimum primary driver strengths associated

794 with a breakpoint. Subplots: (A) Chilika model outputs, primary slow driver: fisher population growth;

795 (B) Easter Island model outputs, primary slow driver = tree clearance; (C) TRIFFID model outputs, 796 primary slow driver = temperature change; (D) Lake phosphorus model outputs, primary slow driver $797=$ phosphorus input. The dashed vertical lines denote the minimum primary driver strength associated 798 with a breakpoint. 

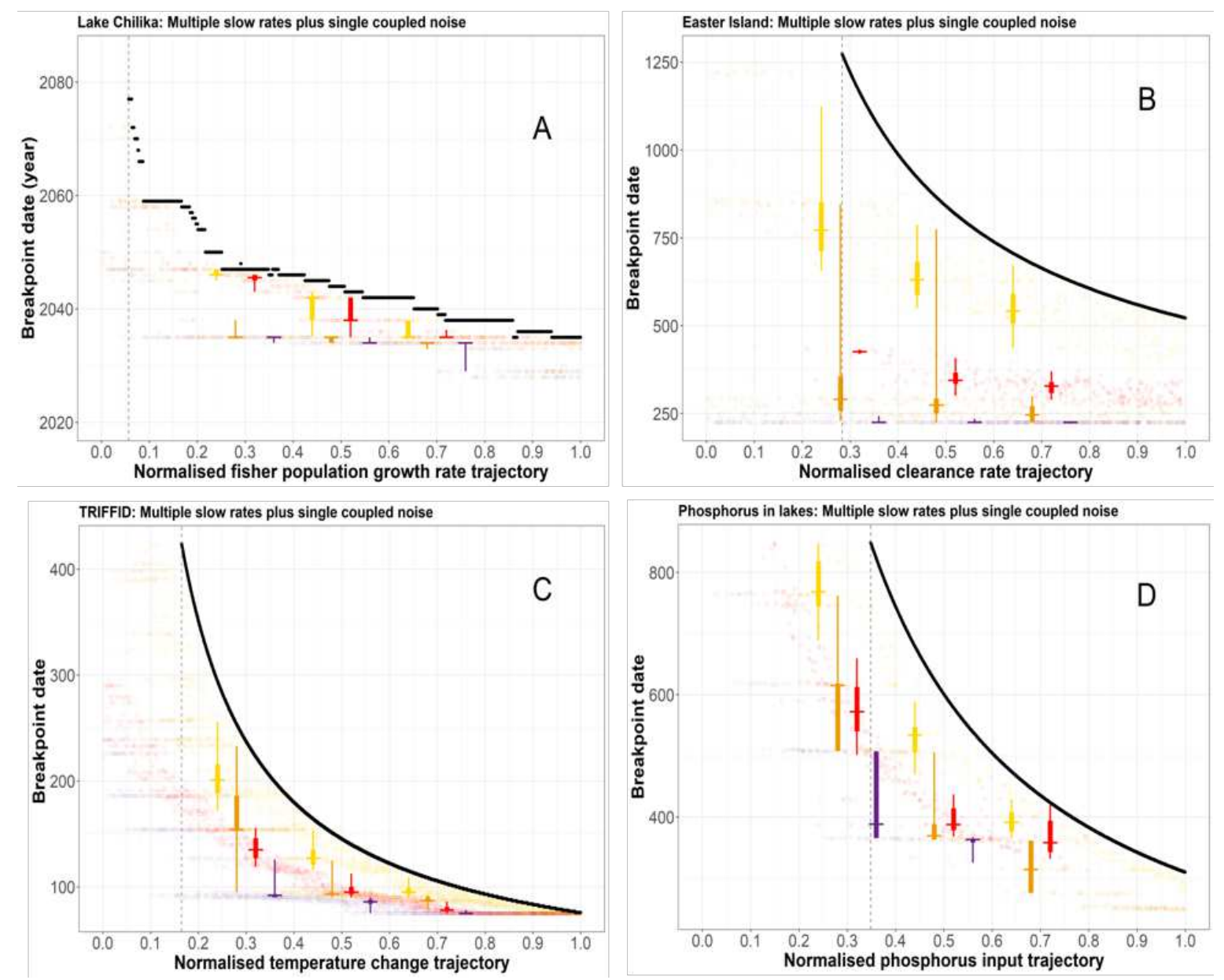

800 Figure S3 - The relationship between the breakpoint date and the primary slow driver (black; normalised between 0 and 1 ) when weak (normalised T values $\leq 0.333$ ) and strong (normalised T values $>0.666$ ) multiple driver trajectories are combined with weak (normalised $\sigma$ values $\leq \mathbf{0 . 3 3 3}$ ) and strong (normalised $\sigma$ values $>0.666$ ) coupled noise $(T=$ trajectory, $\mathrm{N}=$ noise). For each of the scenarios (i.e. driver combinations), the boxplots depict the $2.5 \%, 25 \%, 50 \%, 75 \%$ and $97.5 \%$ breakpoint date percentiles, in each of the following ranges along the $x$-axis: $0.25-0.35,0.45-0.55$, $0.65-0.75$. The dashed vertical lines denote the minimum primary driver strengths associated with a breakpoint. Subplots: $(A)$ the Chilika model , primary slow driver = fisher population growth, additional driver: climate change and fish price; (B) the Easter Island model, primary slow driver = tree clearance, additional drivers: agricultural carrying capacity and tree mortality; (C) the TRIFFID model, primary slow driver = temperature change, additional driver: disturbance rate; $(D)$ the lake phosphorus model,

811 primary slow driver $=$ phosphorus, additional drivers: phosphorus recycling rate, phosphorus

812 sedimentation rate. The dashed vertical lines denote the minimum primary driver strength associated 813 with a breakpoint. 
814 Table S1 - Tipping points triggered by additional drivers below the minimum driver strengths 815 required to collapse the system if only a single driver were in effect.

\begin{tabular}{|l|c|c|c|c|c|}
\hline \multirow{2}{*}{ Model } & \multicolumn{3}{|c|}{$\begin{array}{l}\text { Number of model runs which tipped at primary driver strengths below the minimum } \\
\text { observed to cause a tipping point if only a single driver were in effect }\end{array}$} & $\begin{array}{l}\text { Total runs across } \\
\text { all scenarios } \\
\text { which tipped }\end{array}$ \\
\cline { 2 - 6 } & $\begin{array}{c}\text { Additional } \\
\text { secondary driver }\end{array}$ & $\begin{array}{c}\text { Additional tertiary } \\
\text { driver }\end{array}$ & $\begin{array}{c}\text { Additional secondary and } \\
\text { tertiary drivers }\end{array}$ & Total (\%) & \\
\hline Lake Chilika & 55 & 45 & 133 & $233(1.21 \%)$ & 19,208 \\
\hline Easter Island & 7 & 1018 & 983 & $2008(14.8 \%)$ & 13,574 \\
\hline TRIFFID & 1410 & NA & NA & $2870(12.3 \%)$ & 23,270 \\
\hline $\begin{array}{l}\text { Lake } \\
\text { phosphorus }\end{array}$ & 306 & 669 & 1895 & & \\
\hline
\end{tabular}

816

817

818

819

822

823

824

Table S2 - Tipping points triggered by additional uncoupled noise below the minimum driver strengths required to collapse the system if only a single driver were in effect, where normalised $\sigma$ values $\leq 0.333$ signify 'low noise', normalised $\sigma$ values $>0.333$ and $\leq 0.666$ signify 'mid noise', and normalised $\sigma$ values $>0.666$ signify 'high noise'.

\begin{tabular}{|l|c|c|c|c|c|}
\hline \multirow{2}{*}{ Model } & \multicolumn{3}{|l|}{$\begin{array}{l}\text { Number of model runs which tipped at primary driver strengths below the } \\
\text { minimum observed to cause a tipping point if only a single driver were in effect }\end{array}$} & \multirow{2}{*}{$\begin{array}{l}\text { Total runs across all } \\
\text { scenarios which tipped }\end{array}$} \\
\cline { 2 - 6 } & Low noise & Mid noise & High noise & Total (\%) & \\
\hline Lake Chilika & 28 & 78 & 85 & $191(2.50 \%)$ & 7643 \\
\hline Easter Island & 24 & 93 & 291 & $408(6.57 \%)$ & 6209 \\
\hline TRIFFID & 22 & 103 & 221 & $346(2.02 \%)$ & 47,126 \\
\hline $\begin{array}{l}\text { Lake } \\
\text { phosphorus }\end{array}$ & 8 & 40 & 79 & $127(2.63 \%)$ & 4831 \\
\hline
\end{tabular}

Table S3 - Tipping points triggered by additional coupled noise below the minimum driver strengths required to collapse the system if only a single driver were in effect, where normalised $\sigma$ values $\leq$ 0.333 signify 'low noise', normalised $\sigma$ values $>0.333$ and $\leq 0.666$ signify 'mid noise', and normalised $\sigma$ values $>0.666$ signify 'high noise'.

\begin{tabular}{|c|c|c|c|c|c|}
\hline \multirow[t]{2}{*}{ Model } & \multicolumn{4}{|c|}{$\begin{array}{l}\text { Number of model runs which tipped at primary driver strengths below the } \\
\text { minimum observed to cause a tipping point if only a single driver were in effect }\end{array}$} & \multirow[t]{2}{*}{$\begin{array}{l}\text { Total runs across all } \\
\text { scenarios which tipped }\end{array}$} \\
\hline & Low noise & Mid noise & High noise & Total (\%) & \\
\hline Lake Chilika & 25 & 80 & 86 & $191(2.48 \%)$ & 7691 \\
\hline Easter Island & 85 & 347 & 566 & 998 (9.69\%) & 10,302 \\
\hline TRIFFID & 3 & 42 & 88 & $133(1.30 \%)$ & 10,244 \\
\hline Lake phosphorus & 36 & 129 & 28 & $193(3.98 \%)$ & 4849 \\
\hline
\end{tabular}


834 Table S4 - Tipping points triggered below the minimum driver strengths required to collapse the

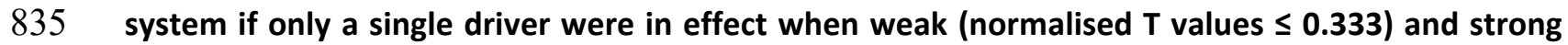
836 (normalised T values $>0.666$ ) multiple driver trajectories are combined with weak (normalised $\sigma$ 837 values $\leq \mathbf{0 . 3 3 3}$ ) and strong (normalised $\sigma$ values $>0.666$ ) uncoupled noise ( $\mathrm{T}=$ trajectory, $\mathrm{N}=$ noise).

\begin{tabular}{|l|c|c|c|c|c|c|}
\hline \multirow{2}{*}{ Model } & \multicolumn{3}{|l|}{$\begin{array}{l}\text { Number of model runs which tipped at primary driver strengths below the minimum } \\
\text { observed to cause a tipping point if only a single driver were in effect }\end{array}$} & $\begin{array}{l}\text { Total runs across all } \\
\text { scenarios which tipped }\end{array}$ \\
\cline { 2 - 7 } & Low T, Low N & Low T, High N & High T, Low N & High T, High N & Total (\%) \\
\hline Lake Chilika & 17 & 25 & 12 & 26 & $80(1.73 \%)$ & 4619 \\
\hline Easter Island & 62 & 100 & 2 & 118 & $282(7.45 \%)$ & 3784 \\
\hline TRIFFID & 142 & 208 & 284 & 347 & $981(6.64 \%)$ & $315(8.92 \%)$ \\
\hline $\begin{array}{l}\text { Lake } \\
\text { phosphorus }\end{array}$ & 26 & 59 & 103 & 127 & 353 \\
\hline
\end{tabular}

Table S5 - Tipping points triggered below the minimum driver strengths required to collapse the

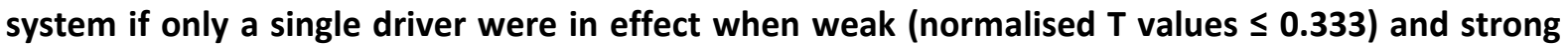
(normalised T values $>0.666$ ) multiple driver trajectories are combined with weak (normalised $\sigma$ values $\leq 0.333$ ) and strong (normalised $\sigma$ values $>0.666$ ) coupled noise ( $T=$ trajectory, $N=$ noise).

\begin{tabular}{|l|c|c|c|c|c|c|}
\hline \multirow{2}{*}{ Model } & \multicolumn{3}{|l|}{$\begin{array}{l}\text { Number of model runs which tipped at primary driver strengths below the minimum } \\
\text { observed to cause a tipping point if only a single driver were in effect }\end{array}$} & $\begin{array}{l}\text { Total runs across all } \\
\text { scenarios which tipped }\end{array}$ \\
\cline { 2 - 7 } & Low T, Low N & Low T, High N & \multicolumn{2}{|c|}{ High T, Low N } & High T, High N & Total (\%) \\
\hline Lake Chilika & 28 & 32 & 23 & 55 & $138(2.67 \%)$ & 6083 \\
\hline Easter Island & 83 & 92 & 2 & 24 & $201(6.04 \%)$ & 3330 \\
\hline TRIFFID & 43 & 73 & 104 & 411 & $331(3.50 \%)$ & 9477 \\
\hline $\begin{array}{l}\text { Lake } \\
\text { phosphorus }\end{array}$ & 7 & 21 & 30 & 42 & $100(3.44 \%)$ & 2911 \\
\hline
\end{tabular}

847

848

849

850

851

852 

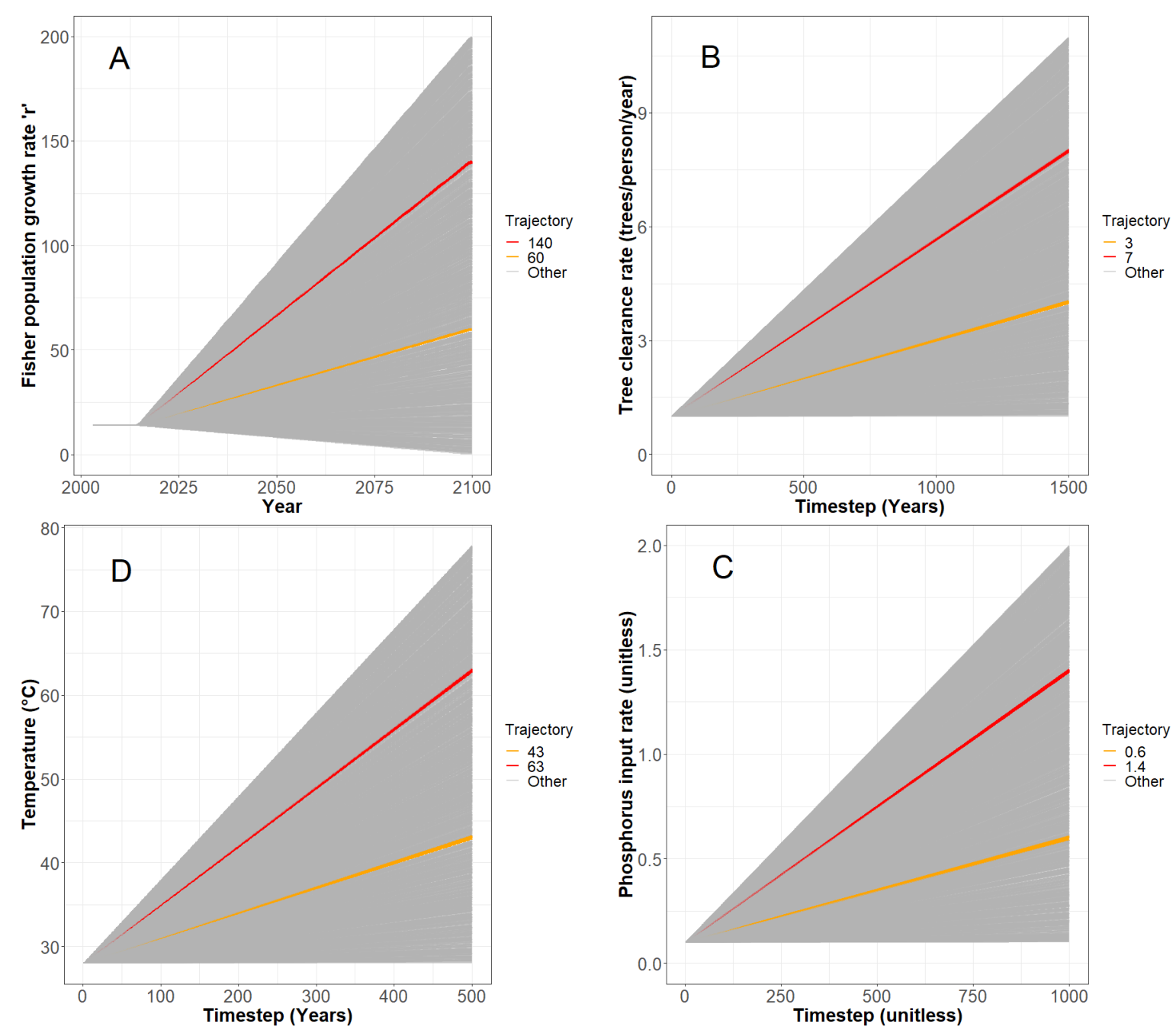

Figure S4 - The future scenario funnels of the four primary (baseline) slow trajectories over the course of their respective model horizons. Subplots clockwise from top-left: (A) array of linear changes in the fisher population growth rate ' $r$ ' (net difference between the crude birth and crude death rates of the fisher population) in the Chilika fishery model; (B) array of linear changes in the tree clearance rate in the Easter Island model; (C) array of linear changes in the phosphorus input rate in the Phosphorus in Lakes model; (D) array of linear changes in the local temperature in the TRIFFID model. As described in Methods Section 2.3, the drivers start at their default values before moving along a randomly selected future trajectory (Table S1). The gradient trajectories representing $30 \%$ and $70 \%$ of the maximum possible trajectories have been identified in orange and red, respectively. The same approach is also used for all secondary and tertiary drivers, evolving along randomly selected linear gradients between 'no change from default' and 'maximum change' by the model horizon. 
Table S6: The number of model simulations constituting each experiment and scenario, as plotted in Figure 2-4 and Figure S1-S3. Each of the model runs were identified to have gone through a tipping point, as per the methodology detailed in Methods Section 3.1 and 3.2. $\mathrm{T}=\mathrm{Trajectory}, \mathrm{N}=\mathrm{Noise}$.

\begin{tabular}{|c|c|c|c|c|c|c|c|c|c|c|c|}
\hline \multirow[b]{2}{*}{ Model } & \multirow[b]{2}{*}{$\begin{array}{l}\text { Experiment } \\
\text { 1: Baseline }\end{array}$} & \multicolumn{3}{|c|}{$\begin{array}{c}\text { Experiment 2: Multiple slow } \\
\text { drivers }\end{array}$} & \multicolumn{3}{|c|}{$\begin{array}{l}\text { Experiment 3a: Single slow } \\
\text { driver plus uncoupled noise }\end{array}$} & \multicolumn{4}{|c|}{$\begin{array}{l}\text { Experiment 4a: Multiple slow drivers } \\
\text { plus uncoupled noise }\end{array}$} \\
\hline & & Secondary & Tertiary & All & Low & Medium & High & $\begin{array}{l}\text { Low } T, \\
\text { Low } N\end{array}$ & $\begin{array}{l}\text { Low T, } \\
\text { High N }\end{array}$ & $\begin{array}{l}\operatorname{High} T \\
\operatorname{Low} N\end{array}$ & $\begin{array}{l}\text { High T, } \\
\text { High N }\end{array}$ \\
\hline Lake Chilika & 3016 & 4603 & 4561 & 7028 & 1429 & 1602 & 1596 & 409 & 388 & 398 & 408 \\
\hline Easter Island & 2118 & 2097 & 4769 & 4590 & 1255 & 1297 & 1539 & 468 & 394 & 231 & 573 \\
\hline TRIFFID & 6833 & 11486 & & & 3354 & 3393 & 3546 & 2028 & 1777 & 1845 & 2292 \\
\hline \multirow{3}{*}{$\begin{array}{l}\text { Lake } \\
\text { phosphorus }\end{array}$} & 2556 & 5425 & 5744 & 9545 & 762 & 733 & 780 & 260 & 283 & 257 & 177 \\
\hline & & & & & \multicolumn{3}{|c|}{$\begin{array}{l}\text { Experiment 3b: Single slow } \\
\text { driver plus coupled noise }\end{array}$} & \multicolumn{4}{|c|}{$\begin{array}{l}\text { Experiment 4b: Multiple slow drivers } \\
\text { plus coupled noise }\end{array}$} \\
\hline & & & & & Low & Medium & High & $\begin{array}{l}\text { Low } T, \\
\text { Low } N\end{array}$ & $\begin{array}{l}\operatorname{Low} T \\
\operatorname{High} N\end{array}$ & $\begin{array}{l}\text { High } T, \\
\operatorname{Low} N\end{array}$ & $\begin{array}{l}\text { High } T, \\
\operatorname{High} N\end{array}$ \\
\hline Lake Chilika & 3016 & & & & 1429 & 1602 & 1596 & 760 & 738 & 759 & 810 \\
\hline Easter Island & 2118 & & & & 2530 & 2603 & 3051 & 340 & 405 & 172 & 295 \\
\hline TRIFFID & 6833 & & & & 1088 & 1095 & 1228 & 614 & 643 & 671 & 716 \\
\hline $\begin{array}{l}\text { Lake } \\
\text { phosphorus }\end{array}$ & 9545 & & & & 824 & 945 & 524 & 96 & 110 & 83 & 66 \\
\hline
\end{tabular}


Table S7: Range of parameter values driving the trajectory changes and addition of noise $(\sigma)$ across the four experiment types (Methods Section 2.1) in each of the four models. The numbers in superscripts denote the corresponding experiment type where the given scenario ranges are active. Experiment $\# 1^{[1]}$ : change in the trajectory of the primary driver only; Experiment $\# 2^{[2]}$ : changes in the trajectories of the primary driver and additional driver trajectories; Experiment $3^{[3]}$ : changes in the trajectories of the primary driver and the addition of noise to the primary driver; Experiment $\# 4^{[4]}$. change in the trajectories of the primary driver and additional driver trajectories, plus the addition of noise to the primary driver. Experiments \#3 and \#4 here include both coupled and uncoupled noise.

\begin{tabular}{|c|c|c|c|c|c|}
\hline Model & External variable & Unit & \begin{tabular}{|l} 
Default \\
value
\end{tabular} & $\begin{array}{l}\text { Range of slow } \\
\text { driver change } \\
\text { trajectories }\end{array}$ & $\begin{array}{l}\text { Noise }(\sigma) \\
\text { range }\end{array}$ \\
\hline 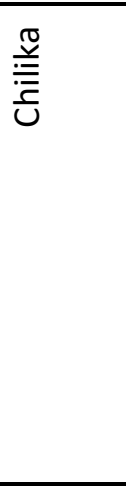 & $\begin{array}{l}\text { Fisher population growth } \\
\text { rate 'r' } \\
\text { Annual rainfall total } \\
\text { change (2081-2100 relative } \\
\text { to } 1986-2005) \\
\text { Annual mean temperature } \\
\text { change (2081-2100 relative } \\
\text { to } 1986-2005) \\
\text { Change in fish price per } \\
\text { unit }\end{array}$ & $\begin{array}{l}\text { Unitless } \\
\% \\
{ }^{\circ} \mathrm{C} \\
\text { INR/kg }\end{array}$ & $\begin{array}{l}14 \\
0\end{array}$ & $\begin{array}{l}-14-186^{[1,2,3,4]} \\
0-30^{[2,4]} \\
0-4.5^{[2,4]} \\
0-2550^{[2,4]}\end{array}$ & $\begin{array}{l}0-100^{[3,4]} \\
0^{[1,2,3,4]} \\
0^{[1,2,3,4]} \\
0^{[1,2,3,4]}\end{array}$ \\
\hline 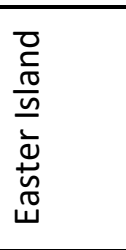 & $\begin{array}{l}\text { Tree clearance } \\
\text { Agricultural carrying } \\
\text { capacity } \\
\text { Mortality rate of trees }\end{array}$ & $\begin{array}{l}\text { Trees/person/ } \\
\text { year } \\
\text { Persons } \\
\text { Trees/year }\end{array}$ & $\begin{array}{l}1 \\
1200 \\
0.01\end{array}$ & $\begin{array}{l}0-10^{[1,2,3,4]} \\
0-6200^{[2,4]} \\
0-0.1^{[2,4]}\end{array}$ & $\begin{array}{l}0-20^{[3,4]} \\
0^{[1,2,3,4]} \\
0^{[1,2,3,4]}\end{array}$ \\
\hline 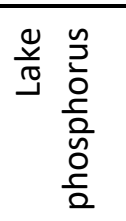 & $\begin{array}{l}\text { Phosphorus input } \\
\text { Recycling rate } \\
\text { Sedimentation }\end{array}$ & $\begin{array}{l}\text { Unitless } \\
\text { Unitless } \\
\text { Unitless }\end{array}$ & $\begin{array}{l}0.1 \\
1 \\
1\end{array}$ & $\begin{array}{l}0-2^{[1,2,3,4]} \\
0-3^{[2,4]} \\
-0.5-0^{[2,4]}\end{array}$ & $\begin{array}{l}0-0.5^{[3,4]} \\
0^{[1,2,3,4]} \\
0^{[1,2,3,4]}\end{array}$ \\
\hline$\frac{\text { 은 }}{\frac{4}{\underline{x}}}$ & $\begin{array}{l}\text { Local temperature } \\
\text { Disturbance rate }\end{array}$ & $\begin{array}{l}{ }^{\circ} \mathrm{C} \\
\text { Trees/year }\end{array}$ & $\begin{array}{l}28 \\
0.2\end{array}$ & $\begin{array}{l}0-50^{[1,2,3,4]} \\
0-2^{[2,4]}\end{array}$ & $\begin{array}{l}0-10^{[3,4]} \\
0^{[1,2,3,4]}\end{array}$ \\
\hline
\end{tabular}

